NBER WORKING PAPER SERIES

\title{
INFORMATION AND BARGAINING THROUGH AGENTS: EXPERIMENTAL EVIDENCE FROM MEXICO'S LABOR COURTS
}

\author{
Joyce Sadka \\ Enrique Seira \\ Christopher Woodruff \\ Working Paper 25137 \\ http://www.nber.org/papers/w25137 \\ NATIONAL BUREAU OF ECONOMIC RESEARCH \\ 1050 Massachusetts Avenue \\ Cambridge, MA 02138 \\ October 2018, Revised October 2020
}

\begin{abstract}
We would like to thank Sebastian Garcia, Andrea Fernandez, Sergio Lopez-Araiza, Enrique Miranda, Isaac Meza, Diana Roman, and Monica Zamudio for superhuman re-search assistance, Vince Crawford, Jonas Hjort and Bentley MacLeod for helpful discussions, and seminar and conference participants at Cambridge, Columbia, Toulouse, ITAM, Monash, NYU - Abu Dhabi, Oxford, Tinbergen, MIT/Harvard, George Mason, Maryland the Latin American Workshop on Law and Economics, and the American Law and Economics Association for comments. All errors are ours. We acknowledge financial support from the Government Partnership Initiative of the Abdul-Latif Jameel Poverty Action Lab (JPAL) at the Massachusetts Institute of Technology, the Economic Development and Institutions program funded by the UK government through UK Aid, and the Asociacion Mexicana de Cultura. We also acknowledge crucial institutional, operational, and human resource support from the Mexico City Labor Court and its president, Darlene Rojas Olvera. The research reported in the paper was carried out with the approval of the ITAM Institutional Review Board. The trial registration number is AEARCTR-0002339. The views expressed herein are those of the authors and do not necessarily reflect the views of the National Bureau of Economic Research.
\end{abstract}

NBER working papers are circulated for discussion and comment purposes. They have not been peer-reviewed or been subject to the review by the NBER Board of Directors that accompanies official NBER publications.

(C) 2018 by Joyce Sadka, Enrique Seira, and Christopher Woodruff. All rights reserved. Short sections of text, not to exceed two paragraphs, may be quoted without explicit permission provided that full credit, including $\odot$ notice, is given to the source. 
Information and Bargaining through Agents: Experimental Evidence from Mexico’s Labor Courts

Joyce Sadka, Enrique Seira, and Christopher Woodruff

NBER Working Paper No. 25137

October 2018, Revised October 2020

JEL No. K31,K41,O43

\begin{abstract}
Well-functioning courts are essential for the health of both financial and real economies. Courts function poorly in most lower-income countries, but the root causes of poor performance are not well understood. We use a field experiment with ongoing cases to analyze sources of dysfunction in Mexico's largest labor court. Providing the parties with personalized outcome predictions doubles settlement rates and reduces average case duration, but only when the worker is present to receive the information. An intervention before plaintiffs contact a lawyer increases pre-suit settlement. The experiment illuminates agency issues among plaintiffs with private lawyers. For most workers, the treatment appears to improve welfare, as measured by discounted payouts and ability to pay bills.

Joyce Sadka

Economics and Law Departments

Instituto Tecnologico Autonomo de Mexico

Mexico City

MX

jsadka@itam.mx

Enrique Seira

Centro de Investigación Económica

ITAM

Ave. Santa Teresa \# 930

Mexico

enrique.seira@gmail.com

Christopher Woodruff

Queen Elizabeth House

University of Oxford

OX1 3TB

UK

and NBER

christopher.woodruff@qeh.ox.ac.uk
\end{abstract}

A data-appendix is available at http://www.nber.org/data-appendix/w25137 


\section{Introduction}

Well-functioning courts underpin markets and constrain private power in developed economies, but courts function poorly in most developing countries. Outcomes are unpredictable, parties are misinformed, and inefficient processes lead to slow decisions and large case backlogs (Djankov et al. (2003)). In addition to raising concerns for justice, poorly functioning courts undermine both the financial (Ponticelli and Alencar (2016) $)$ and real (Boehm and Oberfield (2020); Chemin (2020) ) economies. The effects of poorly functioning courts are increasingly well documented, most convincingly through studies analyzing changes following the creation of new institutions providing legal services for specific activities (Visaria (2009); Lichand and Soares (2014)). However, as Boehm and Oberfield (2020) note, even "Newly created courts tend to...accumulate backlogs over time" (p. 2009). Thus, while the existing literature provides evidence on the importance of well-functioning legal institutions, it is much less informative on how to improve the performance of existing institutions, or how to ensure the continued high performance of the new institutions. This is due in part to a lack of rigorous empirical work aimed at understanding the micro-analytics of court proceedings, and a particular paucity of randomized experiments in courts (Greiner and Matthews (2016)).

To illuminate the causes of dysfunction in courts, we conduct a randomized experiment with active cases in the Mexico City Labor Court (MCLC). The MCLC is responsible for enforcing labor law for all private employers located in Mexico City. Most cases involve workers who claim to have been involuntarily separated from their jobs by employers who then failed to make severance payments to the workers as required under the labor law. Each year the court receives more than 35,000 filings, but resolves less than 30,000 cases. The MCLCs growing case backlog stems in part from its settlement rates, which are low in comparison to those of similar courts in other countries. Taking a cue from the literature on bargaining under asymmetric information, our experimental treatment provides parties with case-specific predictive outcomes, generated from machine-learning models using data from 5,000 concluded cases. We use the experiment to understand how the relationship between plaintiffs and their lawyers affects the settlement and progression of their cases through the court.

Mexico's job-insurance system is based on severance payments made directly by firms to dismissed workers. On paper, the law is straightforward and very favorable for Mexican workers. Dismissed workers are entitled to a minimum severance payments of 90 days' wages and, 
depending on circumstances, substantially more. Payments must be made even if the dismissal is due to loss of business by the firm. However, while the law itself is generous, the framework for enforcing the law disadvantages workers for at least three reasons. First, workers and firms are often informal (Kumler, Verhoogen and Frias (2020)). Wages are paid in part or entirely in cash and there is no formal written contract. In these circumstances, dismissed workers may find it difficult to prove wage levels or even the existence of the labor relationship itself. Second, at the time of hiring, firms often take actions that undermine the workers subsequent claim of unfair dismissal. For example, firms may require the worker to sign an undated letter of resignation as a condition of hiring. Third, while the payments from the unemployment insurance systems used in most countries are made by the government, payments in Mexico are made directly from the firm to the worker. Workers who win a judgment often face challenges in recovering payments ordered by the court from their former employers. The firms can avoid making payments through a combination of transferring assets to other entities, firm bankruptcy, and bribes. With the threat of avoiding payment, firms often negotiate much lower payments even after the court rules against them. Indeed, administrative records show that that, more than half of the time, workers winning a court judgment are unable to recover anything.

We demonstrate the relevance of these disadvantages by using the historical case files to document a set of stylized facts about the functioning of the court. First, the historical data show that plaintiffs receive, on average, only around half of the minimum 90-day compensation called for in the law. Second, although the law stipulates that suits should be adjudicated within three months, more than a third of the cases filed in the court between 2009 and 2012 remained unresolved in early 2016. The backlog of cases is driven in part by low settlement rates: around 55 percent of cases are settled in Mexico, compared with 80 to 90 percent in higher-income countries. Third, parties are overconfident: the sum of the two parties' probabilities of winning far exceeds 100 percent, and both the probability of winning and the expected size of the award are optimistic, particularly on the plaintiff's side, relative to predictions based on historical cases. Fourth, plaintiffs have little knowledge of their legal entitlements. Moreover, even those represented by private lawyers are surprisingly uninformed about the contents of their own lawsuits. Finally, we show that although private lawyers file much larger claims, they do not recover more than public lawyers. After accounting for fees, private lawyers actually recover less than public lawyers.

Working with the court, we conduct an experiment in three phases, which differ in the point 
at which we intervene in the process. In phase 1, we intervene in ongoing cases at any point in the life of the lawsuit. We find that the information treatment increases settlement on the day of treatment by 75 percent, and that settlements are more frequent in cases that are early in the process. In phase 2 , given the potential of earlier interventions to be more effective, we intervene in the first hearing of each case. Although there are more settlements at the first hearing, we find that the effect of the information treatment is of very similar magnitude. In both the first and second phases, we find that the treatment is effective only when the employee is present at the hearing, and only in cases where the employee is represented by a private lawyer 1 Administrative data from 42 months after treatment indicate that an additional 38 percent of the cases in both the control and treatment groups are settled after the day of our intervention; however, the treatment effect and the relevance of the employee receiving the treatment directly remain constant over that time. The importance of the employee's presence for even long-run outcomes suggests that lawyers do not convey the information to their clients. The persistence in the treatment effect indicates that the intervention led to settlement of cases that would not have been settled otherwise. Perhaps most importantly, data on case outcomes from phase 1 and 2 show that the increase in settlements improves the outcomes for the typical plaintiff. These patterns suggest that case trajectories are affected by lawyer-plaintiff agency issues. Given this, in phase 3, we work with a sample of recently dismissed workers who come to the court seeking information about their rights before they contract with a lawyer and file a case. The treatment providing predicted case outcomes is again effective in increasing settlement, this time before a case is filed.

The results of the three experiments suggest that informational asymmetries between the worker and her lawyer are one underlying cause of malfunctioning courts. A majority of plaintiffs earn below the median wage and have modest levels of schooling; more than 80 percent are using the court for the first time. Survey responses indicate that 38 percent of plaintiffs found their lawyer on the sidewalk outside the court building, where many lower-quality lawyers find clients. The workers are wildly overconfident about their chances of winning their lawsuit. We show analytically that the incentives of the lawyers, who have information advantages, do not always align with those of their clients even though private lawyers in the MCLC cases almost always receive a share of the award collected by their plaintiffs. Differences in the ability to diversify

\footnotetext{
${ }^{1}$ Both the choice of lawyer and the presence of the employee at the hearing may be endogenous to outcomes. However, the treatment is orthogonal to either. We discuss this issue in more detail below.
} 
risk and discount rates lead to very different preferences over settlement options between the plaintiffs and their lawyers. Lawyers also charge an initial fee that is generous relative to the time required to file a suit, giving them incentives to file cases even when they have little prospect of winning.

By 2020, almost 90 percent of both treatment and control cases in the first two phases were resolved. This allows us to examine how treatment affects the welfare of plaintiffs. Relative to the control group, those in the treatment group are 6.7 percent more likely to have settled, 7.3 percent less likely to have lost a judgment, and 0.4 percent less likely to have won a judgment. The additional settlements come mainly from cases with modest recovery amounts. When we compare the net present value of the amount collected by plaintiffs in the treatment and control groups, we find that the treatments improved the outcomes for the typical plaintiff. Though making a precise statement about plaintiff welfare is difficult for reasons we discuss in Section 7. surveys two months after treatment show that treated workers in Phase 3 are 7 percent less likely to report not having enough food to eat or being unable to pay for basic services; reported happiness is insignificantly higher with treatment.

Experiments in courts are uncommon. Greiner and Matthews (2016) review the small number of randomized evaluations in the US legal system, finding 50 studies conducted between 1963 and 2015. Most of these examine mediation and alternative dispute resolution, though a handful evaluate programs that affect the use of lawyers. There are likewise very few legal experiments in low-income countries ${ }^{2}$ As a result, there is little credible evidence on the source of delays and the effect of differences in rules and organizational structure. Indeed, given the scarcity of diagnostic information about courts in developing countries, the stylized facts we derive from extensive administrative records contribute to the literature on courts as institutions for development.

The paper also contributes to the literature on experts and moral hazard. The most closely related paper in this literature is Anagol, Cole and Sarkar (2017), who conduct an audit experiment in the Indian life insurance market. They show that agents use their informational

\footnotetext{
${ }^{2}$ Two notable exceptions are Aberra and Chemin (2019), who provide access to lawyers to randomly selected plaintiffs in cases involving land disputes, showing that legal assistance leads to greater investment in land held by the plaintiffs; and Sandefur and Siddiqi (2015), who provide access to paralegals that lower the cost of accessing the formal legal system in Senegal. They find that access to the formal legal system is particularly valuable for those most likely to be disadvantaged in the customary legal system - for example, women who are suing men. Kondylis and Stein (2018) use an abrupt change in procedural rules rolled out across six civil courts in Senegal to identify the effect of the reforms; the authors find that the new regulation resulted in in faster pre-trial phases of cases.
} 
advantage to induce clients to make decisions that are favorable to the agents' interest. There is much more extensive observational evidence that agents take advantage of superior information in diverse settings: Schneider (2012) in Canadian auto repair shops; Emons (1997) among doctors in Switzerland; and Levitt and Syverson (2008) among real estate agents in the US ${ }^{3}$

A third related literature is that of bargaining in the field. Courts are a disciplining device for a bargaining game between the parties to the case. The canonical Rubinstein (1982) bargaining framework shows that bargaining outcomes are immediate and efficient where information is complete, delays are costly, and parties bargain by making alternating offers. However, the efficiency result breaks down if parties have asymmetric information (Myerson and Satterthwaite (1983)). Bargaining may also break down or be delayed if parties are overly optimistic f Our data indicate that both misinformation and excessive optimism are characteristics in the MCLC cases. Most of the relevant bargaining literature constructs a game between two parties, but court cases typically involve four parties: the plaintiff, the defendant and the lawyers representing either side. This distinction is relevant if agency is important. Note that, theoretically, the addition of lawyers may result in either more- or less-efficient outcomes. Gilson and Mnookin (1994) model court cases as prisoners dilemmas in which the parties play once and the lawyers play repeatedly. As such, the lawyers may cooperate when the players would not, generating more-efficient outcomes. Ashenfelter and Dahl (2012) examine data from arbitration cases involving emergency services unions and municipalities in New Jersey. In a context in which the parties sometimes represent themselves and sometimes are represented by lawyers, they show that lawyer-agents provide positive benefits to the party they represent.

Finally, we contribute to the literature on the effects of information provision and decision making. Information has been shown to improve decision making in wide range of other contexts: in the functioning of private markets (Andrabi, Das and Khwaja (2017); Belot, Kircher and Muller (2019) ), in schooling decisions (Jensen (2010); Dizon-Ross (2019)), and in political institutions (Chong et al. (2015); Reinikka and Svensson (2011)). Our results focus on courts and suggest that it is important that the information be conveyed directly to the party affected by the decisions.

${ }^{3}$ Hubbard (1998) and Hubbard (2000) suggest that reputation is effective in controlling agency in the automobile emissions testing market in California. However, in labor courts, the development of reputations among lawyers is limited both because plaintiffs typically use the court only once, and because the plaintiffs seldom connect with one another.

${ }^{4}$ See Yildiz (2011) for a review of the related theory. Overoptimism may also reflect self-serving bias (Babcock and Loewenstein (1997)). 
The rest of the paper proceeds as follows: We begin by describing the context and the Mexican labor law in Section 2, We then detail the data from both administrative records and surveys of litigants and lawyers in Section 3 . Section 4 uses those data to describe a set of stylized facts that motivate our experiment. Section 5 describes the experimental protocol and Section 6 the results. We discuss the welfare implications of the results in Section 7 and conclude in Section 8 .

\section{The Context}

Gerard and Naritomi (2019) shows that while unemployment insurance is the most common job-displacement insurance system in higher-income countries, severance payment programs are the norm in Africa, Asia and Latin America. Mexico's system of severance payments fits this pattern. Mexican workers dismissed from their job for almost any reason are entitled to 90 days' wages and often substantially more, with payments made directly by firms to workers. Severance payment provisions in the private sector are governed by federal labor law in Mexico, with adjudication of disputes in most industries assigned to state-level labor courts 5 We work with the Mexico City Labor Court, the state court serving Mexico City. Each year, the MCLC receives more than 35,000 new cases and concludes fewer than 30,000 cases. Its portfolio of 100,000 active cases is therefore not only large but growing.

Lawsuits filed by dismissed workers claiming they have not received severance payments owed to them account for over 95 percent of MCLC filings. These cases are assigned to one of 20 "subcourts" according to the industry in which the plaintiff was employed. In the first phase of the project, we worked with Subcourt 7, which deals mainly with firms in the retail automotive and transport services industries. In phase 2, we expanded to four additional subcourts specializing in industries such as private education, security, restaurants, retail banking, large department stores, and medical services. In phase 3, we worked with dismissed workers approaching the court who might ultimately file a case assigned to any of the 20 subcourts.

We describe the Mexican Labor Law and the court procedures in more detail in Appendix A. Plaintiffs may be represented by either private or public lawyers. Private lawyers typically charge around 2000 MXP (USD 100) to file a case, and then receive 30 percent of any amount recovered by the worker. Lawyers from the Public Attorney's office are paid a fixed wage and

\footnotetext{
${ }^{5}$ Disputes in a few "strategic" industries named in the Mexican constitution - oil and gas, pharmaceuticals and auto manufacturing, for example are handled by a federal-level labor court.
} 
do not charge their clients for services. Employers most often respond to a suit in one of three ways: denying the existence of a labor relationship, offering reinstatement, or claiming the worker resigned voluntarily and producing a letter of resignation signed by the employee ${ }^{6}$ High levels of informality make it more difficult for plaintiffs to prove employment relationships and easier for employers to hide assets. These strategies decrease the likelihood that workers who win a judgment or collect the compensation the court awards them.

The parties reach a settlement in around 55 percent of the cases. Cases that settle usually do so within a year of filing. In the absence of settlement, cases typically involve at least six to eight hearings spread over several years. The hearings are conducted by administrative assistants to the judge, but the judge of the subcourt makes all rulings, based on the written record prepared by the assistants. Judgments within three years of filing are rare. Even when workers win their suit, a large proportion of firms do not pay the judgment voluntarily. The plaintiffs must then pursue seizure of assets through officers of the court. Firms have many ways of avoiding asset seizure, for example by declaring bankruptcy or transferring assets to another entity. In more than half the historical cases we code, workers winning the suit are not able to collect any payment.

The challenges for workers arise from informality on several levels. Even workers employed formally and registered with the Mexican Social Security Administration are often paid part of their wages off-books and in cash (Kumler, Verhoogen and Frias (2020)). Workers will generally only be able to recover based on the formal part of their wages. Firm assets are also unregistered. Hence, the court cannot place liens on assets at the time of its ruling. Finally, the process of notification is hampered by corruption at all stages (Aldeco Leo, Kaplan and Sadka (2014)). Corruption is likely to be a particular issue at the asset-seizure stage, when the gain from avoiding notification is clearest for the firms.

\section{Data}

We use both administrative records and survey data. We describe these data briefly here, and in more detail in Appendix A. Through an agreement with the court, we had access to the experimental case files and all of the historical case files from the court. The case files register all the legally relevant information in the lawsuit. Given the scarcity of evidence on the

\footnotetext{
${ }^{6}$ In a large range of low to mid-level jobs, entering employees are obliged to sign a letter of resignation (or a "blank letter") in advance. After firing, the firm adds a date to the letter.
} 
functioning of courts, we view the construction of this data itself as a contribution of the paper.

We conducted the first phase of the experiment in Subcourt 7 between March and May, 2016 and the second phase in Subcourts 2, 7, 9, 11, and 16 between October 2016 and February 2017. In Phases 1 and 2, we intervened in case hearings where both parties had been notified and were therefore obligated to attend the hearing. We conducted Phase 3 between May 2017 and August 2018 with a sample of dismissed workers who had not yet filed a case. In all three phases, we carried out very brief surveys of the plaintiffs and lawyers when they were present, though in Phase 2 the survey was very limited for logistical reasons.

\subsection{Administrative data}

Historical cases: We began by digitizing the historical case file data with the goal of building predictive models of case outcomes, as we describe below. Given the duration of the average lawsuit, we chose to focus on cases filed in 2011, the earliest year for which the court had digital (pdf) records of all initial case filings. For phase 1, we digitized 2,158 lawsuits filed in 2011 or 2012, assigned to Subcourt 7, and concluded by December 2015. Only 55 of those cases were concluded by a decision of the judge. In order to increase the sample of cases concluded by the judge's decision, we reached back to lawsuits filed in Subcourt 7 in 2009 and 2010, identifying 241 additional case files concluded by a judge's decision. Together with the 2011 and 2012 cases, we use these to calibrate the likelihood of winning and amount collected at trial.

For the second phase of the experiment, we used data from 1,000 concluded cases in each of the five participating subcourts. We again selected cases filed in 2011 and concluded by December 2015. We used all such cases from Subcourt 7, and a random sample of approximately 1,000 cases in each of Subcourts 2, 9, 11, and 16. Thus, the calculator for Phase 2 was calibrated with historical data covering 5005 cases, all filed in 2011 and concluded by December 2015 7

Because we often intervened in the first hearing, the predictive model could only use information included in the initial filing. From the case filing, we capture the amount claimed by the plaintiff, the date of the lawsuit, whether the lawyer is public or private, the worker's gender, age, daily wage, tenure at the firm, and weekly hours worked. The variables are defined in Table A.1 in Appendix A. The basic formula for severance payment in the law is in large part a function of the wage, tenure and hours worked.

\footnotetext{
${ }^{7}$ For phase 1, the calculator used the full set 2,158 cases filed in 2011 and 2012 in Subcourt 7. We also include the 2012 cases from Subcourt 7 in the descriptive data we present in the paper.
} 
We also record the outcome of the suit and the termination date. Cases end in one of five ways: being dropped by the plaintiff, expiring due to lack of activity, a judge's ruling with no collection, a judge's ruling with a positive collection, or settlement between the parties. We record the amount recovered by the worker at the end of the proceedings. The majority of the cases with positive recoveries end in settlement. These are essentially always recorded at the court, in order to assure that the plaintiff does not continue to pursue the case. For cases ending in judgments in favor of the plaintiff, the details of the judge's decision are sometimes complex and somewhat opaque and hence difficult to code. Therefore, we did not capture the details of the decision in the dataset. Note that the amount the plaintiff recovers is often different from the amount awarded by the judge for three reasons: first, the law provides that if the judgment is not enforced immediately, additional lost wages may be added to the award; second, the parties may reach a post-judgment settlement, with the worker accepting a lower payment to avoid the high costs of enforcing payment; and third, the worker may be unable to collect the judgment found by the court, for example because the firm may have no assets that can be seized by the time the judgment is enforced. We show below that in the experimental cases where the plaintiff won a judgment and collected a positive amount, the plaintiff collected only 52 percent of the estimated reward.

In addition to providing the raw material for the prediction calculator, the historical data allow us to construct a set of stylized facts about the functioning of the court. We discuss what the data show with regard to trial length, frequency of settlement, amount collected, the fraction of plaintiffs collecting awards, and so forth, in the next section.

Administrative data for ongoing cases: We code the initial case file data from all of the ongoing lawsuits involved in Phases 1 and 2 of the experiment. We use these data, combined with the predictive model developed with the historical data, to predict the outcome of the lawsuit. We also use the administrative records to determine who attended the hearing on the day of the experiment, whether the lawsuit ended on that day through a settlement, and the amount of money recorded for the settlement. We then repeat the data collection in 2020 around 42 months after the start of each phase of the experiment. Administrative records from late 2019 also allow us to see which of the Phase 3 workers sued or settled. As we noted, settlements are generally registered in court files even for cases that settle out of court, because this is the only way the firm can ensure that the employee does not continue to pursue the case. 


\subsection{Survey Data}

We conducted surveys with parties involved in the experiment in all three phases. In Phases 1 and 2 , these were short surveys at the hearing on the day of the experiment. We interviewed the defendant's lawyer and either the plaintiff, if she was present at the hearing, or her attorney if she was not 8 The survey was conducted before parties were aware of their treatment status. We asked about knowledge of the case file and the relevant law, expected case outcomes, and, where the plaintiff was present, demographic characteristics of the plaintiff.

In Phase 3, our sample is dismissed workers approaching the court in search of information. Our survey in this phase collected demographic data similar to Phases 1 and 2, but we also collected enough information about the worker's employment to be able to use the calculator to make predictions on the worker's own case outcomes. In the first two phases, the relevant employment data came from the case file itself, but in Phase 3, the workers had not yet filed a case. In Phase 3, we also conducted telephone follow-up surveys two weeks and two months after the initial contact. The follow-up surveys recorded actions taken after our initial interaction, and elicited updated beliefs about case outcomes. For example, we asked workers if they had talked to a lawyer, and if so, how they had found the lawyer(s). We also asked whether they had filed a suit, settled, or decided not to pursue any claim, and collected a measure of life satisfaction and difficulty in paying bills. We conducted at least one of the two telephone surveys with 89 percent of the sample. Survey questions and response rates from all three phases are discussed in more detail in Appendix A.

Table 2 shows summary statistics of the cases for each of the three phases of the experiment. We use the administrative data for the first two phases and the survey data from Phase 3. Table A.2 in Appendix A summarizes data from the plaintiff surveys. We find that 58 percent of plaintiffs had at most lower secondary schooling. Plaintiffs with public lawyers were more likely to attend the hearing: 29 percent of workers present at Phase 1 and 2 hearings had a public lawyer, while only 10 percent of the case files in the experiment had a public lawyer. Of those workers who showed up and had a private lawyer, most (nearly 82 percent) said their agreement called for paying their lawyer a fraction of any award (30 percent, on average). Only 7.6 percent were currently employed, and for those not currently working who were searching for a job, the

\footnotetext{
${ }^{8}$ Lawyers for the plaintiff and defendant were almost always present, but the plaintiff was present only 18 percent of the time, and the defendant only 1.4 percent of the time. In the interest of time, we surveyed only one individual from each side of the case. At least one party completed the baseline survey in 71 percent of the cases. Survey compliance rates are detailed in Table A.3 in Appendix A
} 
average reported likelihood of finding a job in the next three months was 58 percent.

\subsection{Construction of the calculator}

In the experiment, we provide personalized predictions on important case outcomes to a subset of plaintiffs and defendants. We developed simple, parsimonious, predictive models using the historical case records. We considered several machine learning models, including boosting, random forest, and regularization methods (e.g., ridge), along with OLS and logit. The construction of the calculator is described in detail in Appendix A, but we summarize the main points here. As we noted, the calculator in Phase 1 was developed using 2,158 cases from Subcourt 7 and the calculator used in Phases 2 and 3 used 5,005 cases from the five participating subcourts. The information we provided to the parties also changes somewhat in each phase, as we describe below.

Our goal was to provide predictions on the expected amount collected by the plaintiff, the duration of the case, and the probability the case ends by being dropped, expiring, judgment with zero recovery, judgment with positive recovery, or settlement. The main explanatory variables were all taken from the initial case filing: daily salary, hours worked per week, tenure at the firm, gender of the plaintiff, type of lawyer, whether or not the worker was registered with Social Security, if s/he was employed in a position of high trust (an 'at-will' worker), the specific claims in the case (reinstatement, overtime, back pay, vacation pay, Christmas bonus, statutory profit sharing, severance pay) and the industry of the firm. We used 70 percent of the data to fit the models and the remaining 30 percent for testing. For each outcome, we used cross-validation to choose the model and variables with the best fit on the testing sample, measured by the correlation between predicted and actual values. Tables A.5 \& A.6 in Appendix A present goodness of fit measures for all the models and highlight those we selected.

The models allow us to produce individualized predictions that we shared with parties present at the hearing in cases randomized into the calculator treatment. Figure 4 displays the template we used in Phase 1. The template shows the minimum legal entitlement based on the law if the plaintiff were to win on the issue of unfair dismissal and the probability the case ends in each of the five possible endings. For each of these five endings, we showed the expected amount recovered by the plaintiff. We also show the expected payout across all endings and the percentage of cases that were still unresolved after three years. In Phase 1, we provided the same information sheet to both sides of the case. For Phase 2 we adjusted the format, first 
to simplify the information so that it could be explained to parties more quickly, and second to address concerns raised by court officials. In particular, conciliators working for the court suggested that we provide the expected settlement amount, conditional on characteristics, and then provide each side with data indicating the contingency they faced if they did not settle. We developed separate templates for the plaintiffs and defendants which are shown in Figure C.2. For the worker, the no-settlement contingency was the percentage of cases where workers collected nothing, and for firms it was the average amount collected by plaintiffs that won judgments. For the firms, we also showed the recovery amount implied by the law. In addition to using the calculator as a treatment in the experiment, we use it to build a proxy of average overconfidence, as we describe below.

There are several potential sources of bias in the predictions based on the historical data. One is that our sample is composed of cases that were concluded when the models were estimated in early 2016, and 29 percent of cases filed in 2011 and 2012 were still ongoing at that time. If concluded and ongoing cases have different potential outcomes, then although our predictions are unbiased for the concluded cases, they may be biased for a random sample of ongoing cases. Note that if cases end in settlement, they almost always do so within the first 24 months after filing. Since the historical data used in the calculator models cover more than 24 months after filing, very few of the 29 percent of historical cases that were unresolved are likely to end in settlement. Therefore, the projected average payment for cases ending in settlement - the most important variable in the calculator information - is not affected by this censoring issue.

For cases ending in other outcomes - being dropped, expiring, or ending in judgment, the censoring is a larger concern. This potential bias was communicated to the parties when the calculator information was provided. We perform two exercises to estimate how large any bias might be. First, we compare characteristics of ongoing cases with those of the historical cases used in the models. In Figure A.1 we show that the two sets of cases are similar on observables 9 Second, we compare the characteristics of completed and continuing lawsuits within the historical data. To do this we drew a random sample of 956 cases filed in 2011 that were not finished by 2015. Figure A.2 shows that these 956 unresolved cases are very similar to the completed cases used to develop the models 10

\footnotetext{
${ }^{9} \mathrm{An}$ exception is that the experimental cases have a higher rate of claiming reinstatement. This is likely because cases demanding reinstatement typically have longer duration, so that they are less likely to be found in a database of concluded lawsuits.

${ }^{10}$ Recall that the sample used to estimate the model also included cases filed in 2008 and 2009 in Subcourt 7.
} 
A second issue is that even if our predictions are unbiased on average, they are not unbiased for any specific case. Parties may have information about the strength of their case that is unobservable to us. Again, we made clear to the parties that the predictions were based on average outcomes, and outcomes of individual cases will vary depending on the circumstances of the case.

Finally, the calculator predictions will build in any biases contained in previous court decisions. For example, if workers collect less because they are unable to prove wage payments made in cash or because firms avoid making payments ordered by the court, then the calculator will implicitly assume these conditions will continue to apply in the future. Although reforming the institutions so that payments more faithfully reflect the law is a goal of current judicial reforms, we believe the calculator faithfully reflected conditions that the parties in our experiment faced. We view the situation as analogous to providing parents and children with accurate information on returns to public schooling. This allows them to make better schooling decisions given the actual quality of education, but may not directly lead to improvements in the quality of schooling. In our case, the goal of the experiment is to uncover the sources of inefficiencies in the courts to allow reformers to focus on the most critical issues while also providing information with which plaintiffs can make more informed decisions given the way the court actually functions.

\section{Outcomes and Expectations: Stylized facts}

We use the administrative and survey data from phase 1 to document a set of stylized facts about the court. These serve as a motivation for the experiment we implement, but also provide some insight on the functioning of the court. We note whether the source of data for each stylized fact is the historical administrative data or survey data.

Fact 1. Plaintiffs receive little (Historical Data): The amount collected is only 20 percent of the amount claimed on average, and 50 percent of what the law mandates.

Figure 1 uses the sample of concluded cases to show the amounts claimed and recovered for the 4 main outcomes: settlement, drop, judgment, and expiry. Both the historical data and the Phase 2 case files suggest that around 55 percent of cases end by settlement, 20 percent are dropped or expire and 25 percent end with a judge's decision 11 For each outcome, the first

\footnotetext{
${ }^{11}$ The percentages show on Figure 1 reflect the outcomes of the cases that were settled by 2015. As we note
} 
bar shows the average amount of money claimed by the plaintiff. The second bar shows the estimated minimum compensation by law based on the details of the cases. We include items stipulated by current law: severance pay of 90 days at the stated wage, one year of end-of-year bonus and vacation pay, and a tenure bonus mandated for unfair dismissal of up to twice the minimum wage for 12 days per year worked. The third bar shows the amount of money collected, on average, including zeros where the plaintiff did not collect anything. The final bar shows the average amount collected conditional on collecting a positive amount. The amount collected is zero in the cases where the lawsuit is dropped, the time expires, the lawsuit is lost, or the lawsuit is won but the plaintiff is unable to collect anything from the defendant. In cases ending with a judgment the worker recovers a positive amount only 24 percent of the time. For either settlements or judgments, the amount received is a small percentage of the amount claimed.

In the 24 percent of court judgments where the worker recovers a positive payment, she receives on average 170 percent of the minimum legal compensation for her case and 37.5 percent of her claim. Figure 1 shows that in expected value, plaintiffs recover less than the minimum compensation according to the law and only 8 percent of their claim in a court judgment. As a result of low recoveries, in a significant percentage of cases with private lawyers, the plaintiff's receives negative (discounted) payoffs. Private lawyers typically charge a fee of around MXN\$2000 (USD 100) to file a case and receive 30 percent of any amount collected by the plaintiff. Figure C.4 shows realized recoveries from our 5,005 historical casefiles. After subtracting filing and contingency fees, around 40 percent of cases filed by private lawyers have a negative realized return. The majority of the filings with negative net recovery are cases that are either judgments without collection or cases dropped or expired. However, around 7 percent of the settlements are also for amounts that imply a negative net present value for the plaintiff.

Fact 2. Long suit duration (Historical Data): 30 percent of trials started in 2011 had not finished by December 2015. Even conditional on reaching a settlement, the average duration is almost 1 year.

Figure 2 shows the distribution of case length for concluded cases by type of case ending. Even conditional on being concluded in December 2015, cases ending in judgment take 2.4 years on average. Given that many of the 30 percent of cases filed in 2011 and still open in 2016 are

later, 30 percent of the cases filed in 2011 or 2012 were unresolved at the end of 2015 . These unresolved cases are very likely to end either in judgment or by being dropped / expired. The percentages in the text account for this censoring. 
likely to end in a judgment, the unconditional average is much higher. Settlements occur, on average, 10 months after filing. Moreover, settlement rates are low by international comparison. Only around 55 percent of MCLC cases are settled. By way of comparison firing disputes are settled after filing in 79 percent of the cases in Australia, in 80 percent of the cases in the United States, and in 90 percent of the cases in Sweden (Ebisui, Cooney and Fenwick (2016)).

The long delays and low settlement rates help to explain the large backlog of cases in the court. Delay has direct costs in the form of court staff time, lawyer fees and the opportunity cost of litigants' time. But delay also harms the parties if, as is likely the case, the plaintiffs discount the future at a higher rate than the defendants. Because awards result in payments from the party with a lower discount rate (the firm) to the party with the higher discount rate (the plaintiff), delay results in a collective welfare loss to the two parties. These delays represent pure efficiency losses.

Fact 3. Inflated expectations (Survey data): The subjective probabilities of winning for plaintiffs and defendants (in the same case) sum to $1.4^{12}$, indicating aggregate overconfidence. There is average overconfidence relative to the calculator's prediction as well.

Excessive optimism of the parties may result in there being no settlement that is acceptable to both parties, even in cases where settlement would be possible with more realistic expectations 13 We asked parties present at the hearing the likelihood they would win the case. We also asked, conditional on the plaintiff winning, what amount would be paid. In Phases 1 and 2, the average expected probability of winning reported by plaintiffs is 0.79 and 0.80 , respectively, while for firm lawyers it is 0.68 in phase 1 and 0.40 in Phase 2. These probabilities sum to 1.47 and 1.20 in the two phases, respectively. Data from the Phase 3 surveys of workers approaching the court suggests that the overoptimism at least initially comes from workers themselves: prior to beginning the process, workers' stated probability of winning was 89 percent.

By comparison, the probability of the worker winning predicted by our calculator in the same cases is 41 percent in phase 1 and 33 percent in Phase 2. In Phases 1 and 2, there are also large differences in the expected amount of the award conditional on winning. Both the worker and her lawyer estimate average amounts more than twice those of defendants. We can build a

\footnotetext{
${ }^{12}$ This is the measure of overconfidence used by Yildiz (2003) to explain delay or conciliation in a theoretical bargaining model.

${ }^{13}$ Yildiz (2011) shows that optimism alone is not enough to explain bargaining delays in a static model. However, excessive optimism can lead to an empty contracting zone so that, in the absence of learning, settlement does not occur even when it be efficient in the absence of optimism.
} 
proxy of overconfidence as the difference between the subjective expectation and the calculator prediction. Figure C.5 in Appendix C plots the distribution of overconfidence for different parties for peso amounts conditional on winning and probabilities of winning, and Table C.5 in Appendix C shows that, in Phase 1, plaintiffs and plaintiff lawyers are equally overconfident both with regard to the probability of winning and the expected amount recovered.

Fact 4. Misinformation (Survey data): Only one-third of plaintiffs understand their main legal entitlement. Only half know what they are asking for in their own suit.

The main legal entitlement for unfair dismissal is 90 days severance pay, a right so fundamental that it is enshrined in the Mexican Constitution and taught in elementary schools. However, Panel (b) of Figure 3 indicates that only 27 percent of plaintiffs responding to the survey know the number of days covered by this entitlement. Even more strikingly, the plaintiffs often do not know what they are asking for in their own suit. In the survey, we asked plaintiffs to: “... mark the items you are asking for in your suit among the following...", listing: Constitutional payment, reinstatement, overtime, holiday bonus, Sunday bonus, and insurance. We assess accuracy by comparing the responses to the case file. Panels (c) to (f) of Figure 3 show the proportion of time the plaintiffs responded correctly to questions regarding elements of their claim. We see that between 20 and 50 percent of respondents answered each element incorrectly. Knowledge of both the law and the case increases in the level of education. Figure 3 also shows that plaintiffs represented by private lawyers are significantly less knowledgeable about the content of their cases than those represented by public lawyers.

Fact 5. Private lawyers file higher claims, but do not recover more (HD): Controlling for observables, private lawyers ask for 86 percent more than public lawyers, but win no more. After paying lawyer fees, the average plaintiff therefore recovers much less with a private lawyer compared with a public lawyer.

The 100 USD fee private lawyers charge upfront far exceeds the marginal cost of filing a standard case. This gives private lawyers an incentive to inflate claims in order to convince workers to file a suit. With regard to case outcomes we find that, conditioning on five basic variables coded from the initial filing 14 , private lawyers ask for 86 percent more, on average. But the ratio of the amount their clients recover to the amount demanded is 5.7 percent lower for

\footnotetext{
${ }^{14}$ The variables are: gender, at-will worker, tenure, daily wage, weekly hours
} 
private lawyers. The result is that the average recovery is insignificantly lower (by 0.5 percent) for private lawyers. We verify that this is the case in Table C.1.

While the amount recovered is the same for public and private lawyers, plaintiffs receive all of the recovered amount with a public lawyer, and only about 70 percent of the recovered amount with a private lawyer. Hence, plaintiffs with public lawyers receive much larger payouts than plaintiffs with private lawyers, conditioning on characteristics. Of course, these data are only descriptive, and we make no attempt to adjust for the endogenous selection of lawyers beyond the five control variables described above.

\section{Experimental Intervention}

The stylized facts presented above show an environment in which workers are uninformed about their legal entitlements and their own lawsuit, and parties to the case are overconfident on average. Our experiment is designed to address a fundamental question: Given these conditions, does the provision of personalized statistical predictions increase settlement rates?

\subsection{The treatment}

Each phase of the experiment compares the effects the provision of statistical predictions of case outcomes against a control group. During the experimental window in Phases 1 and 2, hearings for which both parties were formally notified were assigned to either the treatment arm or the control group. In the third phase, individuals were assigned to treatment or control based on the day they approached the court. We describe the treatments here, and also a describe a placebo treatment that was implemented in Subcourt 7 during a later period and that was designed to show that experimenter effects are not driving outcomes.

The Calculator: Subjects in the treatment arm received a personalized prediction of their case's expected outcomes based on the statistical model described above and the covariates of their own case. The predictions were presented in a single sheet of paper like the one shown in Figure 4, which was used for Phase 1, 15. We extracted the data needed to customize the calculator predictions from the initial filing (Phases 1 and 2) or from a survey (Phase 3). The data were typed into a user interface. This was done in the presence of the parties in Phase

\footnotetext{
${ }^{15}$ The format and content change somewhat in Phases 2 and 3. Examples of those information sheets are shown in Appendix C, Figures C.2 and C.3
} 
1, but for logistical reasons, away from the parties in Phases 2 and 3. The predictions were then printed and given to all of the parties present at the hearings in phases 1 and 2 , and to the worker in Phase 3. A highly trained enumerator working for the research team spent about 5 minutes explaining to the parties the meaning of the numbers. The enumerators explained that these were only statistical approximations and that they were based on concluded cases from historical records. Enumerators gave no additional legal advice. Where the treatment was administered at a hearing, after explaining the calculator information, the enumerators asked the parties if they wanted to delay the start of their hearing for a few minutes to negotiate with the assistance of a court conciliator.

Placebo: 13 months after the end of the treatments in Phase 1 of the project, we implemented an additional treatment arm in Subcourt 7. We were concerned that simply making parties aware of the court's conciliation services, or that the presence of research assistants and the carrying out of surveys, might change the behavior of the parties. With this in mind, we implemented a "placebo" treatment in which we provided a leaflet (see Appendix C Figure C.9 describing the role of conciliators in the court process. The leaflet was provided in format similar to the calculator information, but rather than quantitative predictions it simply said: "Do you know that you could resolve this conflict today? Conciliation is fast, free, confidential and impartial. Subcourt 7 has conciliators. Ask for help!". If a party receiving the placebo treatment asked to talk with the conciliators, our enumerators showed them where they were situated.

\subsection{Implementation}

The first phase of the experiment started in Subcourt 7 on March 2, 2016 and continued daily for 12 weeks. The "subcourt" is not a single courtroom, but rather a room with a waiting area and eight counters conducting simultaneous hearings. Subcourt 7 manages about 55 hearings per day. Each night the court gave us a list of hearings scheduled for the following day, along with their notification status. We worked with the subset of hearings for which both parties were duly notified and therefore required to be present. Among the 20 case files meeting this criterion on a typical day, we excluded hearings scheduled to start at the court's opening hour of 9 AM because the court did not want to delay the start time of the first hearings of the day 
for fear of causing cascading delays through the day ${ }^{16}$ Note that cases are assigned to hearing times randomly, so our agreement not to consider 9 AM hearings does not compromise the validity of the experiment. On a typical day, this reduced our sample by around 1.5 cases. In what follows we focus on the remaining sample of roughly 18.5 cases per day. In the first phase, the sample cases were at different stages of the process - that is, not all were new suits ${ }^{17}$

After receiving the list of cases for the following day, we randomized the eligible cases in equal proportions to the treatment and control group 18 Control cases followed business as usual, except for the surveys we administered. Each morning we set up a survey table and a calculator module in the waiting area just outside the hearings counters. The hearings were displayed on a screen and parties were called up by the subcourt judge's assistants. Except for the 9 AM hearing slot, the start time of hearings is typically delayed, and we carried out surveys and treatments during parties' waiting time.

Table 1 shows details of the treatments. We began by administering the baseline survey. The survey was conducted blind to the experimental assignment for both the parties and our enumerators. We were able to isolate the survey area from the calculator treatment area, and so avoid contamination, because our sample was only about 18 cases per day. All the parties present were asked to complete the survey, but compliance was optional and in about 70 percent of the hearings, at least one party completed the survey 19 Treatment status was revealed after the baseline survey, and parties were channeled to their assigned experimental condition and given the appropriate treatment protocol described above.

The implementation of the experiment differed slightly in Phase 2. First, randomization was at the case level in Phase 1 and at the day level in Phase 2. This change was made for logistical reasons, given that during the Phase 2 we were working with a larger number of the subcourts. The second is we intervened in cases at all stages of the process during Phase 1, but

\footnotetext{
${ }^{16}$ On occasion, there were in excess of eight cases arriving for 9 AM hearings. In these instances, we were able to include some hearings scheduled at 9 AM in our sample.

${ }^{17}$ The experiment in phase 1 also included a second treatment arm, in which parties were referred to the court conciliator. We focus here exclusively on the calculator treatments, leaving the conciliator treatment to future work.

${ }^{18} 34$ of the 705 phase 1 cases had more than one hearing during the experimental window. We were not able to determine that a case was coming into the experimental sample for a second time, and hence the case was again randomized into treatment or control. For the analysis, we delete the data from the second occurrence of any case, and define the treatment status as the assignment the first time we interacted with the case.

${ }^{19}$ In Phase 1, those completing the survey were told that they would be asked to complete a followup survey after their hearing and were informed they would receive a prize if they did. However, compliance with the posthearing survey was much lower, as parties did not want to stay after their hearing ended. We do not use these post-hearing survey data for any of the main analysis, though it is included in some of the additional analysis shown in the appendix.
} 
focused on cases holding their first hearing in Phase 2. All first hearings are held on Fridays. Otherwise, the protocol was changed only slightly from Phase 1.

We randomize across Fridays in each of the 5 subcourts during the experimental window. To save time, we shortened the survey and we pre-filled and pre-printed the calculator. The subcourts did not agree to allow us to delay the hearings, so if after receiving the calculator the parties wanted to negotiate with one another, they themselves had to request a delay in the hearing to sit with the court conciliator.

The placebo treatment was implemented in ongoing cases, with hearings Monday through Thursday, in Subcourt 7 during the phase 2 experimental window. For convenience, we randomized the placebo at the bi-weekly level with cases during two weeks given the placebo treatment daily and cases in two adjacent weeks serving as a control group without any intervention. For both groups we coded the variables in the case file and recorded whether there was a settlement on the day of the hearing.

\subsection{Integrity of the experiment}

Table A.3 in Appendix A shows treatment and survey compliance rates for the first two phases of the experiment. We define compliance as the parties being present and willing to receive the treatment. The table shows compliance for each party and at the case level. At least one party received the treatment in 80 percent of cases in phase 1 and 87 percent in Phase 2. We estimate the intention to treat (ITT) in all reported results. Table A.4 in the Appendix C shows that the variables are well balanced across the experimental groups in both phases: only 6 out of 23 tests are significant, 2 at the 5 percent level and 4 at the 10 percent level.

\section{Results}

The historical data and survey responses show that plaintiffs are overconfident and uninformed about the law and even their own case. Settlement rates are low and case durations are long. Our intervention aims to understand if there is a connection between these two sets of facts: If we increase information and reduce overconfidence, do we observe an increase in settlement rates? 


\subsection{Effects on settlement}

Given that treatment is randomized, we estimate the causal effect of treatment by estimating the following equation by OLS:

$$
y_{i t}=\alpha_{t}+\beta_{t j} T_{i j}+\gamma X_{i}+\epsilon_{i t}
$$

The constant $\alpha_{t}$ estimates the mean for the control group, while $T_{j}$ indicates assignment to the calculator treatment arm. Thus, $\beta_{t}$ estimates the ITT effect at a given point in time $t$. We estimate separate regressions for each $t$, with $t$ indicating the day of the hearing or 42 months after treatment (the latter measured in January 2020 for Phase 1 and July 2020 for Phase 2), or two months after treatment in Phase 3. $X_{i}$ is a vector of controls for case characteristics, including subcourt dummies. Finally, since the effect may differ according to which parties received the treatment, we also interact the two treatment arms with an indicator for whether the employee was present (EP) when we delivered the treatment, while controlling for EP itself. In Phase 2, we add subcourt fixed effects.

The first six columns of Table 3 focus the short-term outcome of same-day settlement. The dependent variable is a dummy for whether there was a settlement on the day of the intervention 20 The first two columns of Table 3 use data from Phase 1 of the experiment; columns 3 and 4 use data from the second phase of the experiment; and column 5 combines data from the first two phases. Column 1 shows that 6 percent of the control cases in Phase 1 settle on the day of the hearing, while the settlement rate of the treatment group is approximately 5 percentage points higher. The treatment effect is significant at the five percent level.

Column 3 shows that in the second phase of the project, 16 percent of the cases settled on the day of the hearing. Recall that the second phase was conducted with cases holding their first hearing, and the higher settlement rate likely reflects this fact. ${ }^{21}$ However, the effect of the calculator treatment is similar in magnitude to that in the first phase: settlement rates on the day increase by 3.9 percentage points in the treatment group compared with control, an effect that falls just below the .10 significance level.

Columns 2 and 4 show our second main result: the treatment effect occurs only when the

\footnotetext{
${ }^{20}$ We use a linear probability model throughout, but the results are robust to other specifications. Column 1 of Table C.6 reports the results of column 5 using a probit specification to show robustness.

${ }^{21}$ Indeed, regressing a dummy variable indicating settlement on treatment using the combined Phase 1 and Phase 2 data shows that there is no difference in settlement rates in the two phases once we control for the age of the case at the time of treatment.
} 
employee is present. In these regressions, we interact treatment with a variable indicating the plaintiff herself was present, while also including a variable indicating that the plaintiff was present. First, note that in both Phase 1 (column 2) and Phase 2 (column 4), settlement on the day is much more likely when the employee is present. In the control group, 19 percent of the Phase 1 cases and 27 percent of the Phase 2 cases are settled on the day of the intervention when the employee is present. But treatment increases settlement rates by 15.5 percentage points in Phase $1(0.026+0.129)$ and 14.1 percentage points in Phase 2 when the employee is present. The joint effect of the treatment and the treatment / employee present variables are significant at just below the 5 percent level in Phase 1, but not quite at the .10 level in Phase 2. Moreover, the calculator treatment in either phase when the employee is not present is close to zero and highly insignificant particularly in the second phase (row 1 in columns 2 and 4) ${ }^{22}$ The effect of the treatment when the employee is present increases settlement rates by enough to significantly close the gap with those of developed countries referenced above.

The Phase 2 results provide a replication within the experiment, and the similarity of results in Phases 1 and 2 is reassuring. Combining the samples increases statistical power. We do that in Column 5 using the specification from columns 2 and 4. Not surprisingly, we find very similar treatment effects, with the treatment - employee present interaction effect now itself significant at the 5 percent level, and the effect of the calculator when the employee is not present remaining very close to zero.

The regressions in the first five columns measure the effect of treatment on immediate settlement. The results suggest that lawyers do not act on the calculator information in the absence of their client. But might they share the information with their client after the hearing, producing a delayed effect on settlement? The court's administrative records allow us to track cases over time. Column 7 shows the effect of treatment around 42 months after treatment in December 2019/January 2020 for Phase 1 and July 2020 for Phase 2. The 42-month window allows for several additional hearings in the case, and, indeed, is after almost 90 percent of cases are resolved.

Our third main result is that the effect of treatment does not change materially at any point up to 42 months after the intervention, even though the number of cases settled overall

\footnotetext{
${ }^{22}$ Table C.3 in Appendix C examines balance in key variables in the subsample of cases where the employee is present. Table C.4 in the Appendix C tries to predict EP using case characteristics with mild success. Employees are more likely to attend in cases with public lawyers and when they had a long tenure at the firm, and less likely to attend when they worked longer hours at the firm.
} 
increases substantially. Focusing first on cases where the employee was not present at the hearing, comparing column 5 with column 7 , we see that in the control group, the settlement rate increases from 11 percent to 44 percent. Meanwhile, the effect of the calculator when the employee was not present (row 2) remains a fairly precisely estimated zero (and, indeed, if not slightly negative). Where the employee was present to receive the treatment, the treatment effect also remains almost unchanged over time. The 13 percentage point effect on the day of the hearing drops (insignificantly) to 11 percentage points after 42 months.

Treatment is random conditional on the presence of the employee at the hearing, but we might be concerned with the endogeneity of employee presence itself. While this is fundamentally an external validity issue (since treatment is random conditional on the plaintiff's presence), it is relevant for how we interpret the null treatment effect when the employee is not present. Linking this finding to plaintiff-lawyer agency issues implies that settlement rates would have been higher had the employee been present in the subset of cases where she was not present. We might be concerned that plaintiffs are present when there is potential for the case to be settled, and not present when there is little potential for settlement. However, the long-run follow-up data suggest that the plaintiff's presence on the day is not determinant of settlement in the control group. First, among cases in the control group where the employee was present on the day, the effect of the employee's presence dissipates over time; 42 months after treatment, the effect in the control group is no longer significant (row 2, column 7 of Table 3). Second, among the control group cases where the employee was not present on the day, an additional 33 percent of the cases settled over the following 42 months. Taken together, the results imply that neither the presence nor absence of the plaintiff on the day of the intervention determined settlement in the longer run among the control group cases. On the other hand, settlement in the treatment group was affected by the presence of the employee, both on the day of treatment and in the longer run.

To address any residual concerns with the endoegeneity of the plaintiff's presence, in column 6 we use a control function approach (Wooldridge (2015)), using settlements on the day of treatment as the outcome ${ }^{23}$ Employees are more likely to be present when their hearings are scheduled for one of the first two hearing times (9:00 or 9:30) or the last hearing times (12:00 or 12:30). Hearing times are assigned to cases randomly, and we find that a dummy variable

\footnotetext{
${ }^{23}$ Wooldridge (2015) shows that the control function approach is equivalent to instrumental variables when all specifications are linear, but has advantages when the first stage is non-linear and the second stage includes interaction terms. Both of these hold in our case.
} 
indicating the two early / two late hearing times is highly significant in predicting employee presence ${ }^{24}$ The results indicate that the control function variable itself is significant at the 5 percent level, but the control function has little effect on the magnitude and significance of the interaction between employee presence and treatment.

In Phase 3 of the experiment, we provide the calculator to all of the dismissed workers in the treatment group. Recall that our sample for Phase 3 is dismissed workers approaching the court seeking information. Column 8 shows the treatment on settlement in this sample prior to filing a case. Note that almost two in five (39 percent) of the control group in Phase 3 settle their case by two months after they come to the court. The calculator nevertheless significantly increases settlement: an additional 6.4 percent of workers assigned to receive the calculator treatment settle before filing. This represents 10.4 percent of the 61 percent of workers who would not have settled without treatment, an effect size only slightly smaller than the effect when the plaintiff was present in Phases 1 and 2.

Collectively, the results from Phases 1 and 2 suggest that the lawyers do not share the calculator information with clients. The historical and survey data give us reason to suspect that agency issues might be particularly relevant in cases with private lawyers. In Table 4, we separate plaintiffs according to whether they are represented by a private or public lawyer. We repeat the regressions in columns 5 and 6 of Table 3 for each type of lawyer. The results show that the calculator has an effect only when the plaintiff is represented by a private lawyer ${ }^{25}$ In cases where the plaintiff is represented by a private lawyer, the calculator treatment increases settlement by 19 percentage points when the plaintiff is present, and not at all when the plaintiff is not present. Both of these outcomes change only slightly 42 months later. Moreover, for the control-group cases represented by private lawyers, the effect of employee presence drops from 14 percent to 5 percent over the 42 months, suggesting again that the presence of the employee on the day of the experiment is not in itself determinant of longer-run outcomes in the case. Meanwhile, the treatment has no significant effect on settlement in the much smaller sample of plaintiffs represented by public lawyers. That agency underlies this pattern is also suggested by the data on Figure 3, which shows that plaintiffs using private lawyers are significantly less

\footnotetext{
${ }^{24}$ The first stage regression is shown on Table C.6. We might worry that the time of the hearing affects settlement for reasons other than the plaintiff's presence. We can not rule this out, though we note that in the control group, the time-of-hearing dummy does not significantly predict settlement when the employee is not present $(\mathrm{p}=0.65)$.

${ }^{25}$ As with the employee being present, the choice of lawyer is endogeneous, but the treatment is orthogonal to the type of lawyer.
} 
informed about the contents of their case than are plaintiffs using public lawyers.

One concern is that the parties may believe the calculator information is provided by experts, and so simply agree to settle for the amount presented to them. Figure C.6 in Appendix Cshows the ratio of the agreed settlement to the calculator predicted settlement for all cases ending in settlement. We find that only 29 percent of settlements in the treatment group are within 25 percent of the calculator prediction. This is indeed higher than the 24 percent of controlgroup settlements that fall within this band, but nevertheless suggests that the calculator served only as a guide for initial bargaining. Figure 5 shows the distribution of calculator predictions among cases that settle in the treatment and control groups. The figure shows that the increased settlements come disproportionately from cases with modest predicted settlement amounts.

We read the collective results as indicating that plaintiff-lawyer agency issues are important in this context. Private lawyers appear not to transmit evidence to plaintiffs who are not present to receive the information directly. Of course, it is possible that lawyers do not explain the calculator to their clients because they are unable to recall the meaning of the data provided on the sheet. Given the simplicity with which the data are presented, we find this unlikely. However, even if the failure to pass on the information to their clients simply reflects the difficulty lawyers have in explaining the calculator, the lack of a treatment effect when the plaintiff is not present indicates that the plaintiff does not fully trust her lawyer to make decisions on her behalf 26

A final result, shown in Appendix C Table C.8 is that the placebo has no effect on settlement. The placebo makes parties aware of the availability of the court conciliation process, but provides no information on their own case. We interpret the lack of any effect of the placebo treatment as evidence that the content of the calculator information matters.

\subsection{Case outcomes}

What is the counterfactual outcome for the cases induced to settle by treatment? We examine this first in Table 6 by looking at the pattern of case outcomes in the control and treatment groups for the first two phases of the experiment. We accessed administrative records for the Phase 1 cases in December 2019 and January 2020 and the Phase 2 cases in July 2020. By those dates, only 12 percent of the cases remained unresolved. The outcomes on Table 6 suggest that,

\footnotetext{
${ }^{26}$ The possibility that, when the calculator is explained to both the plaintiff and her lawyer in person, the lawyer does not understand the calculator while the plaintiff does seems highly implausible given that the lawyers have both more education and more experience in labor cases.
} 
in aggregate, the treatment shifts cases from court rulings without collection to settlements. Compared with the control group, settlement rates are 6.5 percentage points higher and court judgments without collection 7.3 percent lower in the treatment group. For the purpose of Table 6. we have classified plaintiffs as winning if the judge rules in their favor, regardless of whether or not they are able to collect the award from the defendants. As we have noted, collection of the award is far from automatic. Indeed, as of the last date we accessed the records, there were 50 cases where plaintiffs had won but not yet collected anything from the defendants. Moreover, in 17 cases where the plaintiffs had won judgment and collected a positive amount, they recovered only 52 percent of the judgment, on average.

\subsection{Effects on overconfidence}

The calculator treatment provides information on likely outcomes of the case. One channel through which the treatment may be effective is by reducing excessive optimism of the parties. Ideally, we would measure beliefs both before and after treatment in both the treatment and control group. We faced operational challenges in constructing this measure in all three phases of the experiment. In Phase 1, the baseline survey data indicate initial overconfidence, but compliance rates with the follow-up survey conducted after the hearing were low, as parties were anxious to leave immediately after the hearing. Nevertheless, the data available from Phase 1, analyzed in Table C.9 in Appendix C, indicate that the treatment lowered the expectations of overconfident plaintiffs. The data from the Phase 3 provide stronger evidence that the treatment tempered optimism, albeit somewhat modestly. As we noted above, in the Phase 3 baseline survey indicates the average worker believed they had an 89 percent chance of winning their case. After presenting them with the calculator information, we elicited expectations a second time. Table 5 shows the difference between the initial and subsequent expectations among the treated sample. After reviewing the calculator information, respondents decreased their probability of winning by 6 percentage points, with 30 percent reporting a lower probability of winning, and 26 percent reducing the amount they expect to recover. However, on average they remain optimistic relative to the historical outcomes, with the probability of winning falling only six percentage points. Note that the regressions on Table 5 use only the treated sample from Phase 3. We initially asked the control group for updated expectations at the end of the baseline survey, but the most common response was agitation that we were asking them the same question again almost immediately, with no reason for their answer to change. As a 
result, we stopped asking for expectations a second time from the control group, However, the small sample from the initial control group surveys suggest that no change in expectations is the appropriate counterfactual for the calculator treatment group.

\subsection{Effects on Case Duration}

We should expect that the increase the number of settlements on the day of the treatment will result in shorter average case duration. Table C.10 in Appendix C shows the results of regressing the duration of cases with a private lawyer against the treatment, employee present and the interaction of the two. We define duration as the number of days from the date of the case filing to the final resolution of the case. For cases still unresolved on the date the records were last checked, we use the date we last checked administrative records as the final date. We begin in the first column of C.10 with an OLS regression of case duration. Consistent with the results from Tables 3 and 4 , we find that the treatment has no effect on case duration when the plaintiff is not present, but reduces duration by almost four months when the plaintiff is present, and effect significant at the .10 level. The OLS specification ignores the censuring of duration. The percentage of cases unresolved as of the last check is both modest (12 percent) and balanced between treatment and control. In Column 2, we use a Cox proportional hazard model, finding very results very consistent with the OLS results in column 1. Finally, in column 3 we exclude from the sample cases that were settled to test whether the treatment had any effect on the trajectory of cases through a channel other than settlement. The small and highly insignificant effect of the treatment, regardless of the presence of the plaintiff, suggest that treatment affected duration only through the increase in the settlement rate.

Faster resolution of cases is a benefit to the court, helping to reduce congestion. It also plausibly increases the welfare of the parties in a situation where the party paying the judgment likely discounts the future at a lower rate than the party receiving the treatment.

\section{Is the Increased Settlement Rate Beneficial?}

The increased settlement rate generated by treatment helps the court meet its goal of reducing the case backlog. There is evidence that reducing backlogs leads to more efficient outcomes in the economy (Ponticelli and Alencar (2016)). But are the settlements induced by treatment directly beneficial to the parties who receive the treatment? A necessary condition for the 
increase in settlements to be beneficial is that the untreated settlement rate is inefficiently low. In this section, we first discuss a simple framework that shows why settlement rates might be inefficiently low. We then analyze the data on the actual outcomes of cases in Phases 1 and 2, and surveys of well-being from Phase 3. Because almost 90 percent of cases in Phases 1 and 2 were resolved by 2020, we are able to measure outcomes for plaintiffs directly, with few cases requiring projected outcomes.

The discussion highlights reasons that the plaintiff's incentives may be misaligned with those of her lawyer, underlining analytical reasons that settlement rates may be inefficiently low. While contingency contracts help to align incentives, they do not eliminate agency issues, particularly with regard to settlement decisions. The empirical analysis shows that the plaintiffs are made better off, on average, by the increase in settlement rates, a finding that is robust to a variety of assumptions on outcomes for the continuing case files.

\subsection{Risk, Discounting and Settlement Incentives}

Treatment increases the probability of settlement, but only when the employee is present. We also find that plaintiffs and the parties collectively are excessively optimistic about their chances of winning their case. While there are four parties involved in the case, for this discussion we focus on cleavages between the plaintiff and her lawyer, which appear to play a central role in the results shown on Tables 3 and 4 ,

The bargaining literature defines the "settlement range" as the range of outcomes that both parties prefer to continued bargaining. The settlement range will be empty if the parties to the dispute are risk-neutral, have identical discount rates and have identical expectations over outcomes. However, if, for example, future outcomes are uncertain and parties are risk-averse, then both parties may prefer to settle for the (certain) expected outcome to remove the risk associated with the uncertain future outcome. Myerson and Satterthwaite (1983) shows that bargaining can break down even when there is a non-empty settlement range, that is, even when both parties prefer settlement over continued bargaining. This classical explanation for sub-optimal settlement rates may be a factor in the generating inefficiently low settlement rates at the MCLC, but the experimental results suggest this is not the only factor. Given the apparent divergence between the plaintiff and her lawyer, we focus on factors that drive wedges in settlement preferences between plaintiffs and their lawyers. Are there primitive factors that lead to plaintiffs preferring to accept a given settlement offer while their lawyers prefer to pursue 
the case? We write down a simple framework in Appendix B that highlights two factors: the ability to diversify risk and differences in discount rates.

The framework formalizes what we view as fairly intuitive points. The plaintiff and her lawyer differ in their ability to diversify risks and, given income differences, likely in their discount rates as well. The framework in Appendix B shows why differences in these two dimensions lead to differences in preferences over taking a certain payoff now (i.e., a settlement) or an uncertain payoff later (i.e., a court judgment).

In deciding between an offer of settlement now and an expected outcome from continuing to pursue the case, each party will account for the difference in timing of the two potential payments, and the uncertainty of the payoff from continuing the case. Taking uncertainty first, lawyers typically handle many cases simultaneously. For example, the median number of ongoing cases among lawyers surveyed in Phase 1 reported was more than 30. Because the outcomes of each of a given lawyer's cases are largely independent of one another, the lawyers are able to diversify the payoff risk inherent in pursuing any single case. Plaintiffs, on the other hand, are a party to only a single case, and therefore cannot diversify that risk. As both intuition and the formal model show, the difference in the ability to diversify risk leads plaintiffs sometimes to prefer the certainty of settlement when their lawyer would prefer the uncertain outcome inherent in pursuing the case: the settlement range between the firm and the plaintiff's lawyer is a subset of the settlement range between the firm and the plaintiff.

The parties may also differ in the rate at which they discount the future. Because plaintiffs will have recently lost a job and will generally have lower incomes even when working, we expect them to be more impatient than their lawyer. For any expected future payout following a judge's decision several years later, the higher discount rate would lead the plaintiff to accept a lower settlement today than her lawyer would be willing to accept. The differences in either the ability to diversify risk or the rate of discount drive a wedge between preferences of the plaintiff and her lawyer, with the plaintiff having a larger settlement range than her lawyer ${ }^{27}$ Again, our objective here is not to be exhaustive in the modeling, but to show that there are plausible reasons that the incentives of the plaintiff and her lawyer are misaligned, and that the misalignment results in too few settlements from the perspective of the plaintiff.

The divergence in preferences of the plaintiff and her lawyer provides an incentive for the

\footnotetext{
${ }^{27}$ This could be offset by differences in the opportunity cost of time of the lawyer. However, lawyers typically manage many cases in the same court building, reducing the opportunity cost of time spent on a given case.
} 
lawyer not to de-bias the expectations of the plaintiffs - for example, by showing the calculator information to the plaintiff. Hence, it provides a rationale for the calculator treatment being effective only when the plaintiff is present to receive the information directly. Finally, the divergence is also sufficient to produce a settlement rate which is sub-optimally low from the perspective of both the plaintiff and the firm.

\subsection{Empirical Evidence on the Induced Settlements and Plaintiff Welfare}

The framework motivates why the plaintiffs might be better off with more settlement. But what do the data say about whether they are made better off by the additional settlements our treatments induce? We examine those data here to provide evidence on the welfare of the plaintiffs induced to settle through the treatments.

Table 6 showed that, on average, the primary effect of treatment was to shift outcomes for the plaintiff from a losing court judgment to a settlement. However, these average outcomes may mask more nuanced underlying patterns. Here we instead analyze the effect of treatment on the amount awarded to the plaintiffs. Table 7 reports the results of regressing the net present value of the amount collected against treatment. For cases with a private lawyer, we reflect legal fees by multiplying the recovery by 70 percent to reflect the plaintiff's share and then subtracting the 2000 MXN up-front fee. We use the amount awarded for both settlements and court judgments. While settlements are collected in all but a very few cases, judgments are not. So for judgments, this will overstate the amount recovered. For the 12 percent of cases that were continuing at the time of the latest update, we assume either that the cases recover the amount that the calculator predicts when their case goes to judgment ${ }^{28}$ (columns 1 through 3), or that they recover nothing (columns 4 and 5). We discount all payments to the date of filing using the discount rate reported reported by the median plaintiff in the Phase 1 survey, which is 50 percent per year ${ }^{29}$ We revisit the assumption on the discount rate below.

In Table 7, we regress the net present value of the amount awarded against treatment, controlling for subcourt fixed effects, year of filing, number of plaintiffs in the case, and use of a public lawyer. In all the regressions, we interact treatment with the presence of the plaintiff on the day of treatment. The outcomes have a very long right-hand tail, and so we have to

\footnotetext{
${ }^{28}$ That is, the recovery conditional on winning the case times the probability they win the case, conditional on the case ending by a court ruling.

${ }^{29}$ Figure C.10 in Appendix C shows the discount rate data elicited from surveys, along with comparable data from the Mexican Family Life Survey for 2009. Microcredit interest rates in Mexico are closer to $100 \%$ per year.
} 
decide how best to handle these. On the one hand, there is no reason to believe they do not represent real outcomes, though in fact many of the largest awards are reduced through posttrial bargaining, or are not collected by plaintiffs. In columns 1 and 4 , we measure the NPV in levels, but winsorize the data at the 95th percentile to reduce the influence of the upper tail of the data. In levels, we find no significant effects of treatment on the NPV of outcomes, either when we use the calculator to impute values for unresolved cases (column 1) or when we impute 0's for those cases (column 4). The measured effect of the treatment when the plaintiff is not present is negative, and the measured effect when the plaintiff is present is positive. However, both effects are highly insignificant. Column 2 instead uses the inverse hyperbolic sine of the outcomes. In the IHS specification, we find that treatment when the plaintiff is not present has no effect, while treatment when the plaintiff is present has a significant positive effect. The pattern in column 2 is similar to the effects of treatment on settlement, showing that the treatment left plaintiffs better off only when the plaintiff was present to receive the treatment directly. The IHS results put increased weight on the left-hand part of the distribution of outcomes. Table 6 shows that the treatment shifts some losing cases to settlement; these are likely to be settlements of modest value. In Figure C.7 in Appendix C, we show the distribution of the amount awarded when the plaintiff was present at the hearing, by treatment round. The distribution of awards in the treated sample has less mass in both tails, the left-hand tail reflecting the results from Table 6, and the right-hand tail perhaps reflecting settlements of cases that would have yielded a higher award if they had proceeded to judgment. Because the IHS specification raises the weight of observations in the left-hand tail and lowers the weight of those in the right-hand tail, the results are more favorable for treatment.

Columns 3 though 5 of Table 7 show that the estimated effects are robust to changes in two key assumptions. First, in column 3, we discount all payments at an annual rate of 30 percent - lower than a typical credit card rate in Mexico during this period. Comparing columns 2 and 3 , we see that the discount rate has almost no effect on the estimated treatment effect. Second, although almost 90 percent of the cases were resolved by 2020, the analysis of the effects of treatment on plaintiff outcomes still depends on assumptions about the remaining unresolved cases. In the first three columns, we assumed that the unresolved cases would all result in plaintiff being awarded the amount predicted by the calculator, conditional on the case proceeding to judgment. In Columns 4 and 5, we instead assume that the plaintiff loses the case and collects nothing. Consistent with this, columns 4 (levels) and 5 (IHS) show that the 
assumption on recovery from the unresolved cases has little effect on the estimated treatment effects, though the effect of treatment when the plaintiff is not present is now marginally significantly negative in the IHS specification. The general robustness to how we impute values for the unresolved cases is perhaps not surprising given that, as we noted earlier, treatment has less effect on settlement among plaintiffs with the highest-value cases (see Figure 5). Further, figure 6 shows that, among the unresolved cases, the calculator predicts much larger recoveries for the treatment cases than for the control cases, conditional on winning a court judgment.

The cases of the workers involved in Phase 3 of the experiment are not far enough along to carry out a similar analysis. However, in the survey conducted two months after the treatment in Phase 3, we asked workers about well being more directly. In particular, we asked them a standard question about general happiness and two questions about difficulties in paying bills. We examine the effect of treatment on responses to these questions on Table 8 . We find no effect on happiness, though the measured effect is positive. However, we do find that the calculator treatment reduced the likelihood they report having had trouble paying bills or not having money for food. These are, of course, short-term impacts, but they are consistent with the higher settlement rates for Phase 3 treatment we observed on Table 3, and also consistent with the importance of cash from settlement while the dismissed workers search for a new job.

In sum, the data provide evidence that the treatments left the plaintiffs are better off when they were present to receive the treatment directly. The gains come both from receiving payment earlier and from receiving payments in cases that would otherwise have been lost. Factoring in risk and the likelihood that the additional settlements come from cases with relatively weak unobservable characteristics, we believe the data show that the typical plaintiff is benefited by the treatment.

\section{Conclusion}

There is substantial evidence that delays in court proceedings are detrimental to the economy. The Mexico City Labor Court is emblematic of dysfunctional courts in lower- and middle-income countries. The MCLC suffers from large backlogs and parties to cases face uncertain outcomes. We show that a straightforward information intervention increases settlement rates both on the day of treatment and in the longer run. The induced settlements remove cases from the court docket more quickly. This contributes to reducing case backlogs - though of course it is possible 
that, at scale, this effect would be partially offset by an increase in the use of the courts by dismissed workers.

Comparing the treatment- and control-group outcomes of the ongoing cases involved in the experiment, we find that the increase in settlements comes almost entirely from cases that would have been lost by the plaintiff. Given the counterfactual of obtaining nothing in these cases, the plaintiffs are clearly better off. There are three reasons to believe that the intervention also improves overall welfare. First, the increase in settlements contributes to reducing the court backlog. We should expect this to have a positive effect on the speed of other cases in process. Evidence from other settings shows positive effect on financial (Ponticelli and Alencar (2016)) and other markets $(\overline{B o e h m}$ and Oberfield $(2020)$; Chemin $(2020))$ from more rapid resolution of cases. Second, the worker-dismissal cases filed in the MCLC involve a payment from one party (the firm) to other parties (the plaintiff and her lawyer). These payments themselves are zero sum. In this setting, it is very likely that the discount rates of firms are lower than those of plaintiffs; in those circumstances, earlier payment will improve the collective welfare of the parties. Finally, reaching and enforcing agreements consume resources of the court; faster settlement reduces these administrative costs. Intervening before cases are filed would appear to maximize these administrative benefits.

The experiment also illuminates several underlying causes of the delays. First, parties to the case, and plaintiffs, in particular, show excessive levels of optimism and limited knowledge of the law. Second, lawyers take advantage of the naivete of the plaintiffs, extending cases when workers would prefer settlement. There are undoubtedly other issues, particularly those related to enforcement of court rulings and delivery of summons leading to longer lags between hearings. Indeed, the results suggest the need for further work to better understand the functioning of the market for lawyers in this context.

More broadly, the results of the experiment suggest the need to merge the insights of the bargaining literature with those from the literature on expert agents. The literature on bargaining and settlements has focused on the relationship between the plaintiff and defendant, and de-emphasized the importance of agency issues between a party and her lawyer. Given the importance of the employee being present to receive the information directly, we should view the bargaining game as one that involves more than two parties. In our case, for example, this is most apparent on the plaintiff's side, where lawyers are informed experts, and plaintiffs are mostly first-time users of the court. The results suggest the need to explore ways to create and 
disseminate information on the quality of lawyers, allowing higher-quality lawyers to develop a reputation.

Finally, the experiment provides a window on the functioning of the court as an institution. In conducting the experiments, we worked closely with the court, and provided officials there with evidence about effective and easily scalable policies; thus, the research has contributed to the policy dialogue on general policies at the court. Indeed, as part of a major constitutional reform of labor law, the court proposed that federal labor law include both statistical information customized to the case, and pre-filing conciliation hearings proposals that were grounded in the evidence from the experiment 30

Joyce Sadka, ITAM

Enrique Seira, ITAM

Christopher Woodruff, University of Oxford

\section{References}

Aberra, Adam, and Matthieu Chemin. 2019. "Does Access to the Legal System Increase Investment? Evidence from a Field Experiment in Kenya." McGill University Working Paper.

Aldeco Leo, Lorenzo, David S. Kaplan, and Joyce Sadka. 2014. "Delay and Corruption: A Simple Model with Empirical Tests." IADB Working Paper.

Anagol, Santosh, Shawn Cole, and Shayak Sarkar. 2017. "Understanding the Advice of Commissions-Motivated Agents: Evidence from the Indian Life Insurance Market." The Review of Economics and Statistics, 99(1): 1-15.

Andrabi, Tahir, Jishnu Das, and Asim Ijaz Khwaja. 2017. "Report Cards: The Impact of Providing School and Child Test Scores on Educational Markets." American Economic Review, 107(6): 1535-63.

Ashenfelter, Orley, and Gordon B. Dahl. 2012. "Bargaining and the Role of Expert Agents: An Empirical Study of Final-Offer Arbitration." The Review of Economics and Statistics, 94(1): 116-132.

\footnotetext{
${ }^{30}$ These proposals were passed by the Federal Senate in mid-2019. See text at: https://goo.gl/9AZ6H7.
} 
Babcock, Linda, and George Loewenstein. 1997. "Explaining Bargaining Impasse: The Role of Self-Serving Biases." Journal of Economic Perspectives, 11(1): 109-126.

Belot, Michle, Philipp Kircher, and Paul Muller. 2019. "Providing Advice to Jobseekers at Low Cost: An Experimental Study on Online Advice." The Review of Economic Studies, 86(4): 1411-1447.

Boehm, Johannes, and Ezra Oberfield. 2020. "Misallocation in the Market for Inputs: Enforcement and the Organization of Production." The Quarterly Journal of Economics, 135(4): 2007-2058.

Chemin, Matthieu. 2020. "Judicial Efficiency and Firm Productivity: Evidence from a World Database of Judicial Reforms." Review of Economics and Statistics, 102(1): 49-64.

Chong, Alberto, Ana L. De La O, Dean Karlan, and Leonard Wantchekon. 2015. "Does Corruption Information Inspire the Fight or Quash the Hope? A Field Experiment in Mexico on Voter Turnout, Choice, and Party Identification." The Journal of Politics, 77(1): 55-71.

Dizon-Ross, Rebecca. 2019. "Parents' Beliefs About Their Children's Academic Ability: Implications for Educational Investments." American Economic Review.

Djankov, Simeon, Rafael La Porta, Florencio Lopez-de Silanes, and Andrei Shleifer. 2003. "Courts." The Quarterly Journal of Economics, 118(2): 453-517.

Ebisui, Minawa, Sean Cooney, and Colin (editors) Fenwick. 2016. Resolving individual labour disputes: A comparative overview. ILO.

Emons, Winand. 1997. "Credence Goods and Fraudulent Experts." The RAND Journal of Economics, 28(1): 107-119.

Gerard, Francois, and Joana Naritomi. 2019. "Job Displacement Insurance and (the Lack of) Consumption-Smoothing." National Bureau of Economic Research Working Paper 25749.

Gilson, Ronald J., and Robert H. Mnookin. 1994. "Disputing through Agents: Cooperation and Conflict between Lawyers in Litigation." Columbia Law Review, 94(2): 509-566.

Greiner, D. James, and Andrea Matthews. 2016. "Randomized Control Trials in the United States Legal Profession." Annual Review of Law and Social Science, 12: 293-312. 
Hubbard, Thomas N. 1998. "An Empirical Examination of Moral Hazard in the Vehicle Inspection Market." The RAND Journal of Economics, 29(2): 406-426.

Hubbard, Thomas N. 2000. "The Demand for Monitoring Technologies: The Case of Trucking." The Quarterly Journal of Economics, 115(2): 533-560.

Jensen, Robert. 2010. "The (Perceived) Returns to Education and the Demand for Schooling." The Quarterly Journal of Economics, 125(2): 515-548.

Kondylis, Florence, and Mattea Stein. 2018. "Reforming the Speed of Justice: Evidence from an Event Study in Senegal." World Bank Policy Research Working Paper, 8372.

Kumler, Todd, Eric Verhoogen, and Judith A Frias. 2020. "Enlisting Employees in Improving Payroll-Tax Compliance: Evidence from Mexico." Review of Economics and Statistics, Forthcoming.

Levitt, Steven D., and Chad Syverson. 2008. "Market Distortions When Agents Are Better Informed: The Value of Information in Real Estate Transactions." The Review of Economics and Statistics, 90(4): 599-611.

Lichand, Guilherme, and Ridrigo R. Soares. 2014. "Access to Justice and Entrepreneurship: Evidence from Brazil's Special Civil Tribunals." Journal of Law and Economics, 57: 459499.

Myerson, Roger, and Mark A. Satterthwaite. 1983. "Efficient mechanisms for bilateral trading." Journal of Economic Theory, 29(2): 265-281.

Ponticelli, Jacopo, and Leonardo S. Alencar. 2016. "Court Enforcement, Bank Loans and Firm Investment: Evidence from a Bankruptcy Reform in Brazil." The Quarterly Journal of Economics.

Reinikka, Ritva, and Jakob Svensson. 2011. "The power of information in public services: Evidence from education in Uganda." Journal of Public Economics, 95(7-8): 956-966.

Rubinstein, Ariel. 1982. "Perfect Equilibrium in a Bargaining Model." Econometrica, 50(1): 97-109.

Sandefur, Justin, and Bilal Siddiqi. 2015. "Delivering Justice to the Poor: Theory and Experimental Evidence from Liberia." World Bank Working Paper. 
Schneider, Henry S. 2012. "Agency Problems and Reputation in Expert Services: Evidence from Auto Repair." The Journal of Industrial Economics, 60(3): 406-433.

Visaria, Sujata. 2009. "Legal Reform and Loan Repayment: The Microeconomic Impact of Debt Recovery Tribunals in India." American Economic Journal: Applied Economics, 1(3): 59-81.

Wooldridge, Jeffrey M. 2015. "Control Function Methods in Applied Econometrics." Journal of Human Resources, 50(2): 420-445.

Yildiz, Muhamet. 2003. "Bargaining without a Common Prior:An Immediate Agreement Theorem." Econometrica, 71(3): 793-811.

Yildiz, Muhamet. 2011. "Bargaining with Optimism." Annual Review of Economics, 3(1): 451-478. 


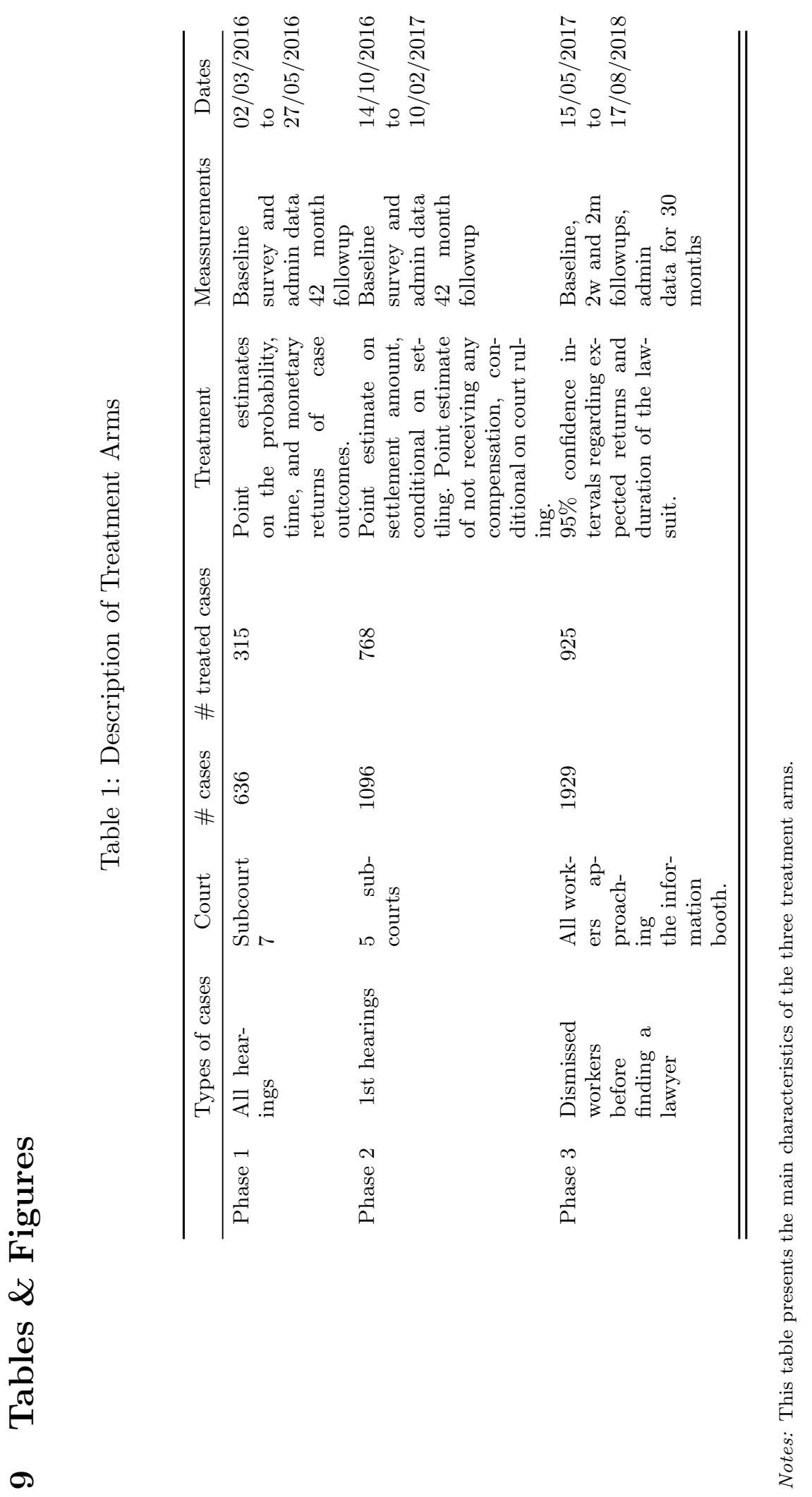


Table 2: Summary Statistics

\begin{tabular}{|c|c|c|c|c|c|}
\hline Variable & HD & HD Subcourt 7 & Phase 1 & Phase 2 & Phase 3 \\
\hline & \multicolumn{5}{|c|}{ Panel A: Outcomes } \\
\hline Win & $\begin{array}{l}0.65 \\
(.48)\end{array}$ & $\begin{array}{l}0.69 \\
(.46)\end{array}$ & & & \\
\hline Amount won & $\begin{array}{c}23917 \\
(56302.54)\end{array}$ & $\begin{array}{c}20358 \\
(47488.41)\end{array}$ & & & \\
\hline Total asked & $\begin{array}{c}343060 \\
(655168.15)\end{array}$ & $\begin{array}{c}301566 \\
(551154.03)\end{array}$ & $\begin{array}{c}598315 \\
(1438490.59)\end{array}$ & $\begin{array}{c}644064 \\
(3860993.2)\end{array}$ & \\
\hline Conciliation & $\begin{array}{l}0.63 \\
(.48)\end{array}$ & $\begin{array}{l}0.67 \\
(.47)\end{array}$ & $\begin{array}{l}0.22 \\
(.41)\end{array}$ & $\begin{array}{l}0.2 \\
(.4)\end{array}$ & \\
\hline Losing court ruling & $\begin{array}{l}0.07 \\
(.25)\end{array}$ & $\begin{array}{l}0.01 \\
(.1)\end{array}$ & & & \\
\hline Winning court ruling & $\begin{array}{l}0.02 \\
(.14)\end{array}$ & $\begin{array}{l}0.02 \\
(.12)\end{array}$ & & & \\
\hline \multirow[t]{2}{*}{ Duration (years) } & $\begin{array}{l}1.02 \\
(.96)\end{array}$ & $\begin{array}{l}0.98 \\
(.71)\end{array}$ & & & \\
\hline & \multicolumn{5}{|c|}{ Panel B: Basic variables } \\
\hline Public Lawyer & $\begin{array}{l}0.1 \\
(.3)\end{array}$ & $\begin{array}{l}0.15 \\
(.36)\end{array}$ & $\begin{array}{l}0.11 \\
(.32)\end{array}$ & $\begin{array}{l}0.06 \\
(.24)\end{array}$ & \\
\hline Female & $\begin{array}{c}0.48 \\
(.5)\end{array}$ & $\begin{array}{l}0.35 \\
(.48)\end{array}$ & $\begin{array}{l}0.41 \\
(.49)\end{array}$ & $\begin{array}{l}0.46 \\
(.5)\end{array}$ & $\begin{array}{l}0.45 \\
(.5)\end{array}$ \\
\hline At will worker & $\begin{array}{l}0.07 \\
(.25)\end{array}$ & $\begin{array}{l}0.06 \\
(.23)\end{array}$ & $\begin{array}{l}0.18 \\
(.39)\end{array}$ & $\begin{array}{l}0.08 \\
(.27)\end{array}$ & \\
\hline Tenure (years) & $\begin{array}{c}4.17 \\
(4.99)\end{array}$ & $\begin{array}{c}3.72 \\
(4.72)\end{array}$ & $\begin{array}{c}153.44 \\
(725.65)\end{array}$ & $\begin{array}{c}4.33 \\
(5.74)\end{array}$ & $\begin{array}{c}3.71 \\
(4.74)\end{array}$ \\
\hline Daily wage & $\begin{array}{c}470 \\
(1100.8)\end{array}$ & $\begin{array}{c}455 \\
(656.22)\end{array}$ & $\begin{array}{c}740 \\
(1360.94)\end{array}$ & $\begin{array}{c}605 \\
(1007.75)\end{array}$ & $\begin{array}{c}323 \\
(634.99)\end{array}$ \\
\hline Weekly hours & $\begin{array}{c}57.33 \\
(15.47)\end{array}$ & $\begin{array}{c}57.36 \\
(15.57)\end{array}$ & $\begin{array}{c}57.37 \\
(16.87)\end{array}$ & $\begin{array}{c}56.15 \\
(13.38)\end{array}$ & $\begin{array}{c}52.88 \\
(15.52)\end{array}$ \\
\hline
\end{tabular}

Notes: The table presents summary statistics of different samples in columns. Column 1 uses the complete sample of cases that started 2011 and were finished by December 2015, for 5 subcourts chosen to represent the majority of the industries at the Mexico City labor court. Column 2 limits these cases to only Subcourt 7, where we ran the phase 1 experiment. Column 3 uses Subcourt 7 casefiles that were subjects of the phase 1 experiment. Column 4 does the same for phase 2 . Panel A shows outcomes: the fraction win for workers, the amount won (includes zeros, actually recovered which may not coincide with what the judge ordered), the total amount asked by the worker in the initial filing, the fraction that settled over the lifetime of the lawsuit, the fraction that reached a court ruling with positive recovery for the worker, the fraction that reached a court ruling with zero recovery, and the duration of the lawsuit in years (a case can have one of 4 types of endings: court ruling, settlement, expiry, and case dropped). Panel B shows some of the main characteristics of the case from the initial filing. These include the fraction that are represented by a public lawyer, the fraction of women, fraction of at will worker (who cannot be reinstated but receive higher severance pay under the law), worker tenure at the firm, daily wage and total hours per week. We include these variables since they are essential for calculating the amount of money that the worker is owed under the law for unfair dismissal. 


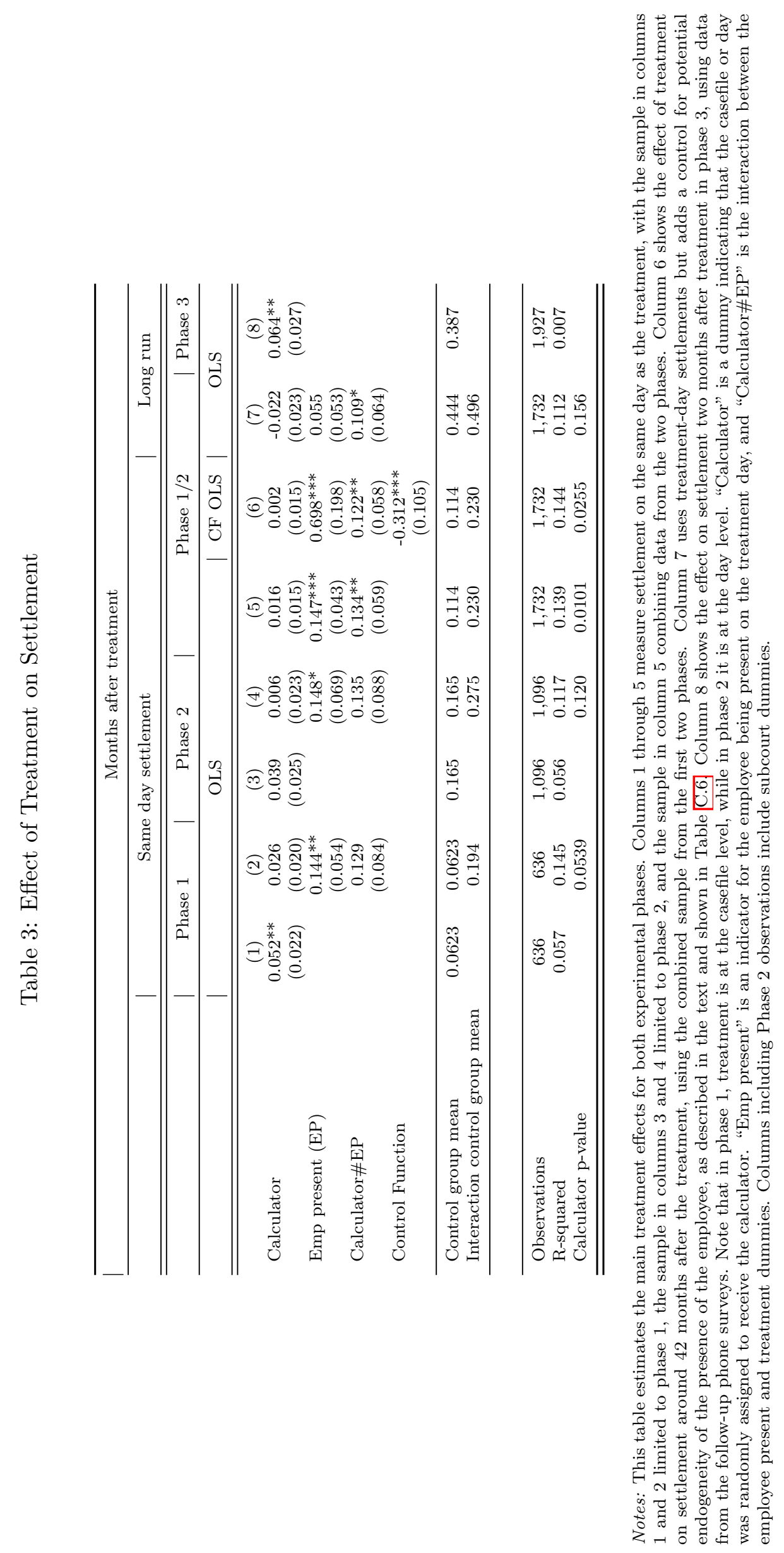


Table 4: Treatment Effects conditional on type of lawyer

\begin{tabular}{lcccc}
\hline & \multicolumn{2}{c}{ Private } & \multicolumn{2}{c}{ Public } \\
\hline & Same day & Long run & Same day & Long run \\
\hline & \multicolumn{4}{c}{ Phase $1 / 2$} \\
\hline \hline Calculator & $(1)$ & $(2)$ & $(3)$ & $(4)$ \\
\hline Emp present (EP) & 0.020 & -0.000 & 0.014 & 0.023 \\
& $(0.017)$ & $(0.027)$ & $(0.049)$ & $(0.134)$ \\
Calculator\#EP & $0.143^{* * *}$ & 0.052 & $0.251^{* *}$ & $0.274^{* *}$ \\
& $(0.044)$ & $(0.065)$ & $(0.111)$ & $(0.135)$ \\
& $0.192^{* * *}$ & $0.154^{*}$ & -0.056 & -0.048 \\
& $(0.066)$ & $(0.089)$ & $(0.125)$ & $(0.181)$ \\
\hline Control group mean & & & & 0.420 \\
Control group interaction mean & 0.229 & 0.446 & 0.269 & 0.538 \\
\hline & & & & 132 \\
\hline Observations & 0.115 & 0.419 & 0.160 & \\
R-Squared & 1,554 & 1,554 & 132 & 0.825 \\
\hline \hline
\end{tabular}

Notes: The table reproduces the regressions in columns 5 through 5 of 3 Columns 1 and 2 use the sample of cases in which the plaintiff uses a private lawyer and the columns 3 and 4 the sample of cases where the plaintiff uses a public lawyer. We are unable to determine whether the lawyer is public or private in 60 of the cases. The dependent variable is a dummy indicating the case was settled by the time indicated on the column heading. All regressions include sub-court dummy variables as controls. See the notes to 3 for further details.

Table 5: Immediate expectation updating

\begin{tabular}{lcccc}
\hline \hline \multicolumn{5}{c}{ Information Experiment: Immediate updating } \\
\hline \multicolumn{4}{c}{ Probability } & \multicolumn{3}{c}{ Amount } \\
\hline & Dummy (lowered) & Continous & Dummy (lowered) & Continous (log difference) \\
Calculator & $(1)$ & $(2)$ & $(3)$ & $(4)$ \\
& $0.30^{* * *}$ & $-0.061^{* * *}$ & $0.26^{* * *}$ & -0.0027 \\
Constant & $(0.021)$ & $(0.0077)$ & $(0.028)$ & $(0.035)$ \\
& -0.000044 & -0.0056 & 0.0023 & -0.0032 \\
& $(0.0098)$ & $(0.0041)$ & $(0.014)$ & $(0.014)$ \\
Source & $2 \mathrm{~m}$ & $2 \mathrm{~m}$ & $2 \mathrm{~m}$ & 578 \\
Observations & 1274 & 1274 & 578 & $315 / 263$ \\
Obs per group & $663 / 611$ & $663 / 611$ & $315 / 263$ & $82 / 90$ \\
Days per group & $90 / 103$ & $90 / 103$ & $82 / 90$ & 0.0060 \\
R-squared & 0.19 & 0.058 & 0.16 & \\
\hline \hline
\end{tabular}

Notes: The table uses the Calculator treatment to estimate its effect on immediate expectation updating. Column (1) regresses an indicator for "decreased expectations" (a variable a dummy $=1$ if the the subjective belief of the probability of winning measured in the immediate follow up survey is lower than in the baseline survey) on treatment arms dummies and basic variable controls. On the other hand, Column (2) regresses the amount by which expectations changed with the same regressors. Recall that the immediate follow up survey was implemented less than 3 minutes after the treatment was given. Using the immediate survey instead of the $2 \mathrm{w}$ or $2 \mathrm{~m}$ survey avoids attrition, however since it was implemented only in the Information Experiment, this table does not have a Panel B. Column (3) is the same as Column (1) except that the dummy refers to amount to be won conditional on winning instead of probability of winning, while column (4) mimics column (2) referring to the quantitative difference of the amount the subject thought she might win. 
Table 6: Case outcomes by treatment arm

\begin{tabular}{l|rrr}
\hline & Control & Calculator & Difference \\
\hline Resolved with recovery: & & & \\
Settled & $41.33 \%$ & $47.82 \%$ & $6.49 \%$ \\
Court ruling with payment & $6.19 \%$ & $5.76 \%$ & $-0.44 \%$ \\
& & & \\
Resolved with no recovery: & & & \\
Court ruling without payment & $26.93 \%$ & $19.59 \%$ & $-7.34 \%$ \\
Expired / Dropped & $13.62 \%$ & $13.74 \%$ & $0.12 \%$ \\
Unresolved: & & & \\
Continues & $11.92 \%$ & $13.09 \%$ & $1.17 \%$ \\
$\mathrm{~N}$ & 646 & 1077 & 1723 \\
\hline \hline
\end{tabular}

Notes: The table shows the status of the experimental cases in Phases 1 and 2 as of January 2020 (for Phase 1) or July 2020 (for Phase 2). These outcomes are taken from the administrative records of the court. "Court ruling with payment" indicates the plaintiff was awarded a judgment by the court. However, XX\% of those awards were uncollected as of January / July 2020 and it is likely that some will never be collected.

Table 7: Recovery after 42 months, Phase $1 / 2$ samples

\begin{tabular}{lccccc}
\hline \multicolumn{5}{c}{ Net Present Vaue of Amount Awarded } \\
\hline & \multicolumn{3}{c}{ Calculator imputed } & \multicolumn{2}{c}{ 0s imputed } \\
\hline & $(1)$ & $(2)$ & $(3)$ & $(4)$ & $(5)$ \\
& NPV & IHS NPV & IHS NPV & NPV & IHS NPV \\
\hline Calculator & -404.6 & -0.447 & -0.423 & -952.0 & $-0.825^{*}$ \\
& $(670.4)$ & $(0.508)$ & $(0.513)$ & $(598.0)$ & $(0.431)$ \\
Employee Present (EP) & $3,023^{* *}$ & -0.175 & -0.215 & $2,940^{* *}$ & 0.245 \\
& $(1,461)$ & $(0.965)$ & $(0.992)$ & $(1,347)$ & $(0.922)$ \\
Calc\#EP & 511.1 & $2.632^{* *}$ & $2.679^{* *}$ & 1,313 & $2.818^{* *}$ \\
& $(1,685)$ & $(1.040)$ & $(1.070)$ & $(1,533)$ & $(1.109)$ \\
& & & & & \\
\hline Control group mean & 5382 & 0.193 & 7123 & 2.205 & 2.477 \\
Control group interaction mean & 7818 & 1.149 & 9803 & 2.716 & 2.945 \\
\hline & \multicolumn{5}{c}{} \\
\hline Observations & 1,698 & 1,698 & 1,698 & 1,698 & 1,698 \\
R-squared & 0.067 & 0.116 & 0.110 & 0.071 & 0.123 \\
Calculator p-value & 0.817 & 0.0664 & 0.950 & 0.0277 & 0.0253 \\
\hline \hline
\end{tabular}

Notes: We measure the net present value of the amount awarded to plaintiffs. The dependent variable in columns 1 and 4 is the NPV, winsorized at the 95th percentile, and in columns 2, 3, and 5 is the inverse hyperbolic sine of the NPV. For cases not yet resolved, columns 1 through 3 impute the calculator predicted value for a court judgment, while columns 4 and 5 impute zeros to unresolved cases. In columns 1, 2, 4 and 5 we discount payments to the date of filing using a discount rate of 3.43 percent per months (50 percent per year). In column 3, we use a discount rate of 2.22 percent per months (30 percent per year). Standard errors are clustered on the day of treatment. All regressions include dummies for the phase, the subcourt, the year the case was filed, the number of plaintiffs in the case and an indicator some information was missing from the case file data. 
Table 8: Phase 3: Effects on welfare

\begin{tabular}{lcccc}
\hline & Happiness & Stopped paying serv. & Lack of money & Works \\
\hline & $(1)$ & $(2)$ & $(3)$ & $(4)$ \\
Calculator & 0.13 & $-0.070^{* * *}$ & $-0.067^{* * *}$ & 0.019 \\
& $(0.12)$ & $(0.024)$ & $(0.025)$ & $(0.025)$ \\
\hline Source & $2 \mathrm{~m}$ & $2 \mathrm{~m}$ & $2 \mathrm{~m}$ & $2 \mathrm{~m}$ \\
Observations & 1459 & 1474 & 1476 & 1476 \\
R-squared & 0.0079 & 0.0073 & 0.0095 & 0.021 \\
\hline \hline
\end{tabular}

Notes: The 2 month survey for Phase 3 included questions measuring proxies for welfare. We asked (Happiness) On a scale of 1 t 10, where 1 means "not happy at all" and 10 means "totally happy", in general, how happy do you feel about your life lately? (Stopped paying serv.) In the past three months have you had to stop paying for a basic service such as electric power, water, or rent due to lack of money? (Lack of money for food) In the past three months, have you lacked money to spend on food one or more days? (Works) Are you currently working? 
Figure 1: Differences in Claims and Compensation by case file outcome - Historical Data

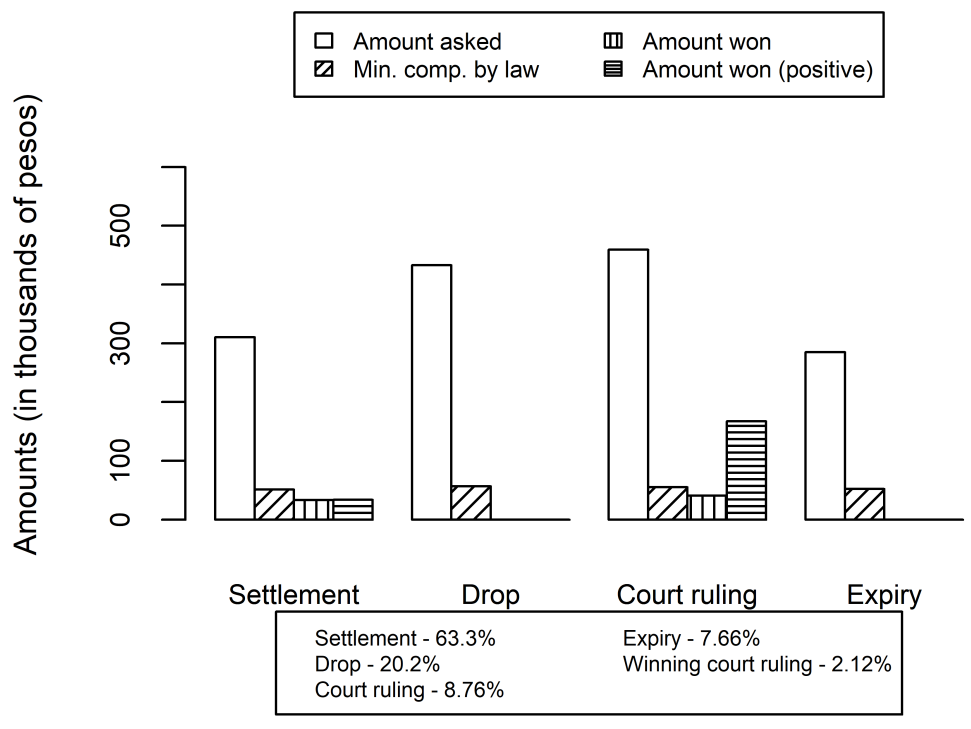

Notes: The figure shows the average amount asked for in the filing, the minimum legal compensation based on the case characteristics, and the amount actually received at the end of the process (overall and conditional on recovering a positive amount). Data are displayed in thousands of pesos by type of case ending, using the 5,005 historical case files. The amounts are discounted at the rate of 50 percent per year (3.43 per month). Cases end in any one of four ways: settlement; being dropped by the plaintiff; court ruling; or expiring from lack of activity. The share of completed cases in the historical case files by type of ending is shown at the bottom. Note that these do not match the share of all cases by type of ending because these data exclude cases that were unresolved at the end of 2015. Workers recover nothing when cases are dropped or expire. We define settlements as an agreement followed by payment, so settlements always imply a positive recovery for the worker. Workers recover a positive amount only 24 percent of the time when the case goes to judgment. These data do not distinguish between the judge ruling against the worker and the judge ruling in favor but the worker being unable to collect anything from the firm. 
Figure 2: Time Duration

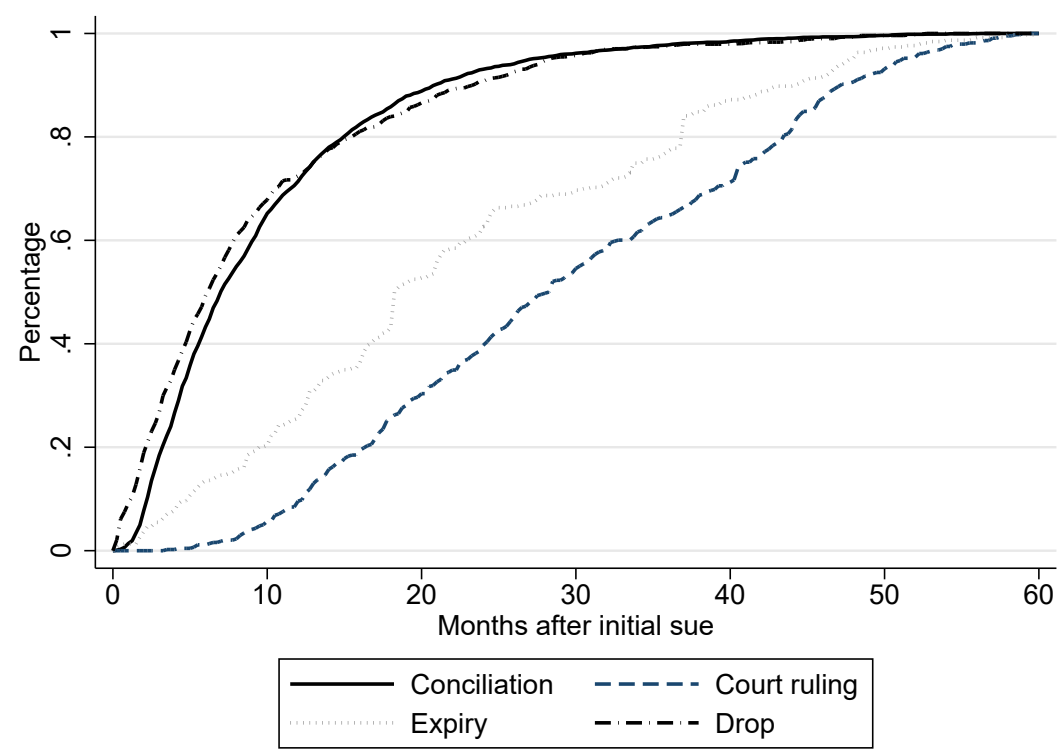

The figure uses the historical data (5005 casefiles) to plot the cumulative distribution of the duration of the case in months, by type of ending, for the 70 percent of cases concluded by the end of 2015 .

Figure 3: Knowledge about Law and their Own Claims in Lawsuit

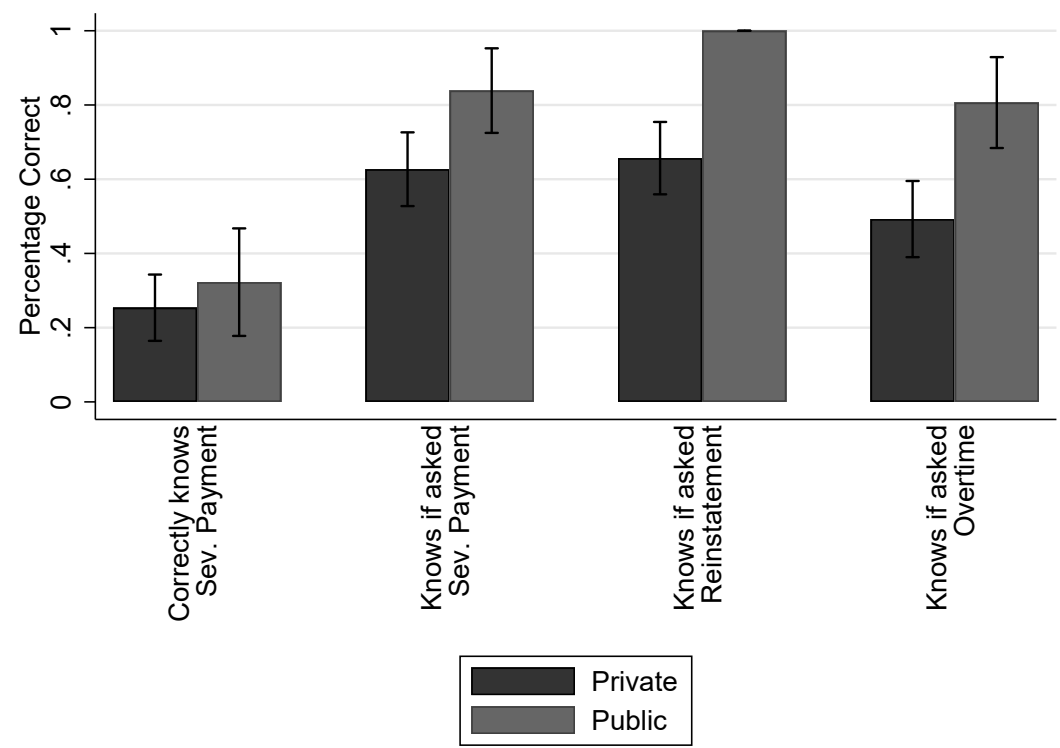

Notes: Data are from baseline survey of Phase 1. The figure shows averages of correct answers for several questions, grouped into: knowledge of the law (panel 1) and knowledge of the content of their own lawsuit (panels 2 to 4). The question for panel (1) is "In the case of unjustified dismissal, law gives you a constitutional indemnification: Do you know how many days of salary this represents?". Panels (2) to (4) correspond to the question: "Mark the benefits that you claimed in this suit: 1. Constitutional indemnification, 2.Medical insurance, 3.Reinstatement, 4.Overtime, 5.Premium for working Saturdays, 6. Aguinaldo (bonus), 7.Don't know". The figure indicates whether the respondent correctly answered items 2,3 and 4 . 
Figure 4: Calculator Treatment Format (example) - Phase 1

\section{CÁLCULO DE COMPENSACIÓN TRABAJADOR}

MARZO 2016

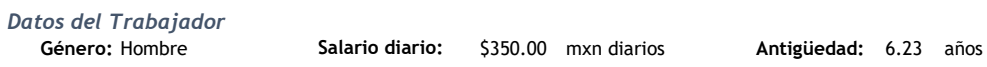

En caso de despido injustificado, la Ley Federal del Trabajo le otorga al trabajador las siguientes prestaciones mínimas:

1.- Indemnización Constitucional - consistente en 90 días de salario diario integrado:

2.- Prima de Antiguiedad - 12 días por año laborado a razón del salario base con tope de 2 veces el salario mínimo:

3.- Aguinaldo - Parte proporcional de 15 días por año, a razón del salario base, del último año calendario laborado:

4.- Vacaciones - Parte proporcional de vacaciones del último periodo laborado, a razón del salario base:

$$
\text { SU COMPENSACIÓN DE LEY: } \quad \$ 44,109.68
$$

¡IMPORTANTE! Después de 3 años, el $48 \%$ de los juicios NO ha concluido.

Ahora le mostramos resultados de juicios concluidos y que son SIMILARES al suyo. Nos basamos en 4500 expedientes de 2009, 2010, 2011 y 2012.

\begin{tabular}{|l|c|rl|c|}
\cline { 2 - 5 } \multicolumn{1}{c|}{} & $\%$ & \multicolumn{2}{|c|}{ Tiempo estimado } & Cantidad pagada \\
\hline Convenio & $65.11 \%$ & 0.86 & años & $\$ 26,052.29$ \\
\hline Desistimiento & $25.62 \%$ & 0.65 & años & $\$ 0.00$ \\
\hline Caducidad & $3.40 \%$ & 2.94 & años & $\$ 0.00$ \\
\hline Laudo con pago & $3.41 \%$ & 2.39 & años & $\$ 50,925.21$ \\
\hline Laudo sin pago & $2.46 \%$ & 1.01 & años & $\$ 0.00$ \\
\hline
\end{tabular}

Tomando en cuenta las posibilidades de ganar y el proceso de ejecución, los datos estadísticos indican:

$$
\text { SU COMPENSACIÓN ESPERADA: } \quad \$ 18,699.32
$$

Recibí impresión. Entiendo que son datos estadísticos que no influyen en mi proceso ni afectan mis derechos.

No. Expediente / Año : 9999/2013 Firma:

Notes:The figure shows an example of the calculator use in phase 1 treatments. The top half described the entitlement by law if the judge rules in favor of the plaintiff, based on data in the case filing. The second half shows what fraction of cases end which way, the average duration and amount for each ending, and the expected value ex-ante saliently in red in the bottom box. The worker and firm name are removed from the example shown here. Parties were told that this information comes from a statistical exercise based on completed historical cases, and that it gives average prediction based on variables of the initial lawsuit described in the calculator treatment. 
Figure 5: Calculator predictions for Settled Cases

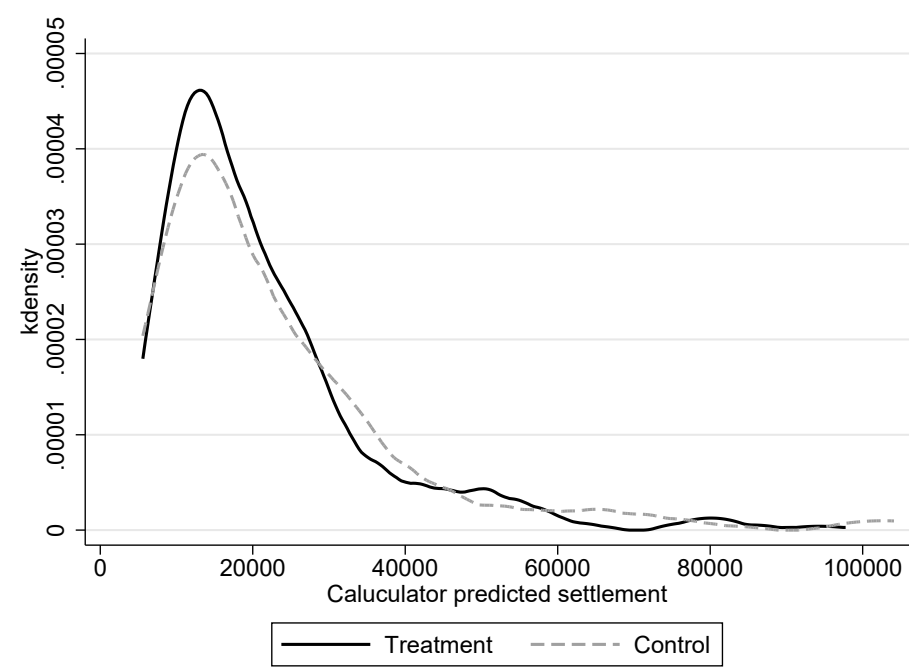

Notes: This figure shows the distribution of settlement amounts predicted by the calculator for treatment and control cases ending in settlement. Data are truncated at the 99th percentile to compress the scale.

Figure 6: Unresolved Cases: Calculator Prediction Conditional on Court Win

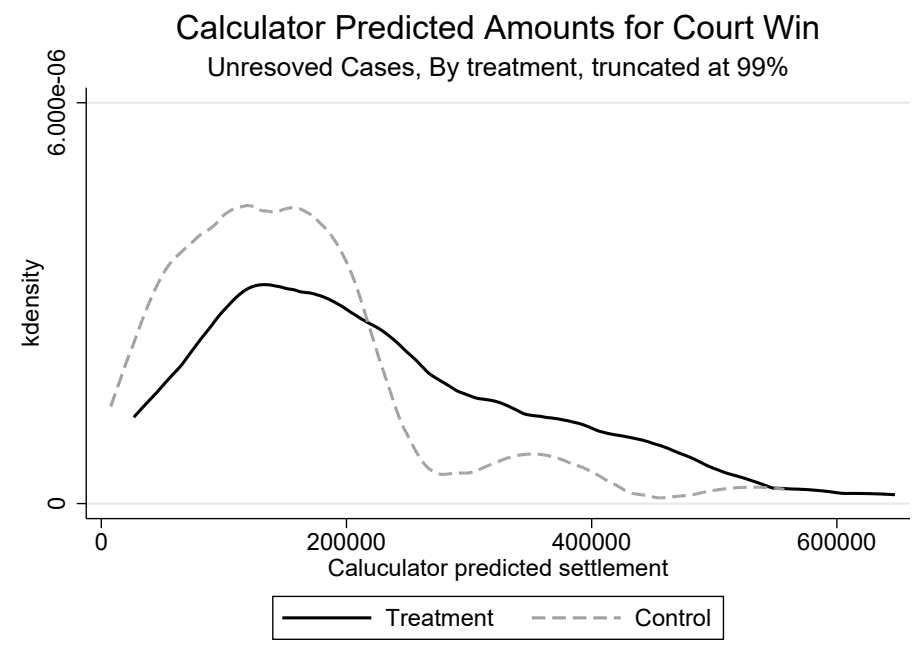

Notes: This figure presents the distribution of recovery amounts predicted by the calculator, conditional on winning a judgment, for treatment and control cases that were unresolved at the time of last data access. Data are truncated at the 99th percentile to compress the scale. Note that the differences between predicted outcomes in treatment and control reflect in part the fact that more of the unresolved cases in the treatment group are from phase 2, and hence higher-value cases. Figure C.8 in Appendix C shows the distributions by phase. The patters are similar though somewhat more muted. 